\title{
Halogen Atoms in the Protein-Ligand System. Structural and Thermodynamic Studies of the Binding of Bromobenzotriazoles by the Catalytic Subunit of Human Protein Kinase CK2
}

\author{
Honorata Czapinska, ${ }^{\perp}$ Maria Winiewska-Szajewska, ${ }^{\perp}$ Anna Szymaniec-Rutkowska, Anna Piasecka, \\ Matthias Bochtler,* and Jarosław Poznański*
}

Cite This: J. Phys. Chem. B 2021, 125, 2491-2503

Read Online

ACCESS | Lلll Metrics \& More | 回 Article Recommendations | sl supporting Information

ABSTRACT: Binding of a family of brominated benzotriazoles to the catalytic subunit of human protein kinase CK2 (hCK2 $\alpha)$ was used as a model system to assess the contribution of halogen bonding to protein-ligand interaction. $\mathrm{CK} 2$ is a constitutively active pleiotropic serine/threonine protein kinase that belongs to the CMGC group of eukaryotic protein kinases (EPKs). Due to the addiction of some cancer cells, CK2 is an attractive and wellcharacterized drug target. Halogenated benzotriazoles act as ATPcompetitive inhibitors with unexpectedly good selectivity for CK2 over other EPKs. We have characterized the interaction of bromobenzotriazoles with hCK $2 \alpha$ by X-ray crystallography, lowvolume differential scanning fluorimetry, and isothermal titration

Interaction of bromobenzotriazoles with the ATP binding pocket of human CK2 calorimetry. Properties of free ligands in solution were additionally characterized by volumetric and RT-HPLC measurements. Thermodynamic data indicate that the affinity increases with bromo substitution, with greater contributions from 5- and 6substituents than 4- and 7-substituents. Except for 4,7-disubstituted compounds, the bromobenzotriazoles adopt a canonical pose with the triazole close to lysine 68, which precludes halogen bonding. More highly substituted benzotriazoles adopt many additional noncanonical poses, presumably driven by a large hydrophobic contribution to binding. Some noncanonical ligand orientations allow the formation of halogen bonds with the hinge region. Consistent with a predominantly hydrophobic interaction, the isobaric heat capacity decreases upon ligand binding, the more so the higher the substitution.

\section{INTRODUCTION}

CK2, formerly designated as casein kinase II, is a pleiotropic serine/threonine kinase found in all eukaryotes. ${ }^{1}$ The holoenzyme is a heterotetramer, consisting of two catalytic $\alpha$ - and/or $\alpha^{\prime}$-subunits and two regulatory $\beta$-subunits. ${ }^{2}$ Unlike other kinases, in particular signaling cascade ones, CK2 is a constitutively active enzyme. It phosphorylates substrates with serine/threonine in regions enriched in acidic residues. The enzyme particularly favors targets with an acid or a phosphorylated serine residue at the +3 position relative to the substrate $\mathrm{S} / \mathrm{T} .{ }^{1} \mathrm{CK} 2$ belongs to (or according to some classifications, is closely related to) CMGC kinases that in addition to $\mathrm{CK} 2$ also comprise cyclin-dependent kinases ( $\underline{\mathrm{CDKs}}$ ), mitogen-activated protein kinase ( $\underline{\mathrm{MAPK}}$ ), glycogen synthase kinase (GSK), and cyclin-dependent kinase-like kinases (CDK-like kinases). ${ }^{3}$

The physiological role of animal CK2 is understood at least partially from the loss of function phenotypes in mice. ${ }^{3}$ Disruption of the CK2 $\beta$-subunit gene leads to a cellautonomous defect and early embryonic lethality, even though the noncatalytic $\beta$-subunits are not required for CK2 activity. The loss of either $\alpha$ - or $\alpha^{\prime}$-subunits leads to milder phenotypes, presumably due to the overlapping roles of the two variants. Among them, $\alpha$ seems to have a broader function than $\alpha^{\prime}$ since $\alpha$ is required for embryonic development, ${ }^{4}$ whereas $\alpha^{\prime}$ appears to be important only for spermatogenesis. ${ }^{5}$ Studies of mammalian CK2 substrates have identified a wide variety of proteins, including many targets involved in gene expression and protein synthesis but also signaling. CK2 appears to have a general antiapoptotic role. ${ }^{6}$ Thus, some cancer cells are more susceptible to CK2 inhibition than nonmalignant cells. Attempts to exploit this "CK2 addiction"7 are underway, using the orally available inhibitor Silmitasertib (CX4945). ${ }^{8-10}$ Possible indications include gastric cancer, ${ }^{11}$ hematological malignancies, ${ }^{12,13}$ and cholangiocarcinoma. ${ }^{14}$

Received: November 13, 2020

Revised: March 1, 2021

Published: March 9, 2021 
From a structural biology perspective, CK2 kinases are well characterized. The first structure was reported for a maize $\alpha$ subunit $^{15}$ and was followed by the structure of the human holoenzyme containing all four subunits. ${ }^{16}$ At present over 200 structures of CK2 enzymes with various inhibitors have been deposited in the public Protein Data Bank (PDB) repository, and many more are available in commercial databases. The CK2 $\alpha$ subunit has a typical eukaryotic protein kinase (EPK) fold $^{17}$ with a smaller N-terminal lobe consisting mostly of $\beta$ strands and the functionally important $\mathrm{C}$-helix and a larger $\mathrm{C}$ terminal lobe that is predominantly $\alpha$-helical and harbors catalytically relevant loops. The active site region contains the typical elements for an EPK. ${ }^{18,19}$ Based on a large number of crystal structures and homology to PKA, a model for catalysis has been developed, ${ }^{19}$ involving two $\mathrm{Mg}^{2+}$ ions, $\mathrm{Mgl}^{2+}$ and $\mathrm{Mg}^{2+}$, that coordinate the $\beta$ - and $\gamma$ - and $\alpha$ - and $\gamma$-phosphates of the ATP cosubstrate, respectively. Most catalytic residues are contributed from the C-terminal lobe. An aspartate (D175) from the DFG motif (DWG in hCK2 $\alpha$ ) coordinates $\mathrm{Mg}^{2+}$ and $\mathrm{Mg}^{2+}$. Another aspartate (D156), from the Y/HRD motif ( $\mathrm{HRD}$ in $\mathrm{hCK} 2 \alpha$ ), is thought to accept a proton from the substrate during catalysis. An asparagine (N161) anchors $\mathrm{Mg}^{2+}$. The $\mathrm{N}$-terminal lobe of $\mathrm{CK} 2 \alpha$ contributes a lysine (K68) from the N-loop and a glutamate (E81) from the Chelix. The lysine $\varepsilon$-amino group interacts with $\alpha$ - (and $\beta$-) phosphates of the ATP cosubstrate and is positioned by a salt bridge to the glutamate.

Several characteristic features distinguish CK2 from most other EPKs (as reviewed in refs 17 and 20). As a constitutively active kinase, CK2 is typically, although with some exceptions, ${ }^{21}$ crystallized with the C-helix and activation loop in the active conformation. ${ }^{20}$ The active form is secured intramolecularly by an $\mathrm{N}$-terminal segment that has been described as the functional equivalent of cyclins activating cyclin-dependent kinases. ${ }^{20}$ The hinge region between the Nand C-terminal lobes adopts a unique conformation that has been cited as the structural explanation for the CK2 specific promiscuity to accept either ATP or GTP as the cosubstrate for the phosphorylation reaction. ${ }^{22}$

Benzotriazoles and in particular their halogenated derivatives have long attracted interest because of their pharmacological properties. The best studied of these compounds is 4,5,6,7tetrabromobenzotriazole (TBBt), the ATP-competitive inhibitor of type I (i.e., binding to the kinase in the active conformation). ${ }^{23}$ As the ATP pockets of EPKs in the active conformation are very similar, ${ }^{18} \mathrm{TBB}$ could be expected to inhibit a broad spectrum of kinases. Surprisingly, this is not the case. After the initial demonstration of its inhibitory activity against CK2 (and not CK1), ${ }^{24}$ it was soon shown to be highly selective for CK2, inhibiting to a significant extent only CDK2 and GSK $3 \beta$ of the CMGC group and PHK (phosphorylase kinase) of the CaMK family. ${ }^{25}$

Recently, much effort has gone into the design of bisubstrate analogue CK2 inhibitors that are based on benzotriazole scaffolds, often in the tetrabrominated form. ${ }^{26-29}$ Moreover, there have been efforts to extend the benzotriazole skeleton on the triazole side to better explore the full size of the purinebinding cavity. ${ }^{30}$ A derivative of tetrabromobenzimidazole (TBBi), SEL24-B849, which inhibits PIM and FLT3 kinases, is under development as a potential drug for hematological malignancies. $^{31}$

The promising pharmacological profile of $\mathrm{TBBt}$ has triggered our extensive investigations of the entire series of halogenated and particularly brominated benzotriazoles. ${ }^{32-37}$ We have determined the inhibitory activity of all nine possible isomers of bromobenzotriazole against $\mathrm{hCK} 2 \alpha{ }^{32}$ as well as their binding affinity to the enzyme (using several complementary biophysical methods). ${ }^{33-35}$ The studies demonstrated that 4,5,6- and 5,6-bromobenzotriazoles are nearly as potent as inhibitors of hCK $2 \alpha$ as TBBt. In contrast, 5-, 4,5-, 4,6-, and 4,5,7-bromobenzotriazoles bind $\mathrm{hCK} 2 \alpha$ with substantially lower affinities, and 4,7- and 4-bromobenzotriazoles virtually do not bind to the enzyme. We have also determined physicochemical parameters of the free ligands in aqueous solution, including solubility, $\mathrm{p} K_{\mathrm{a}}$ for the dissociation of the triazole proton, ${ }^{32}$ and a large set of hydrophobicity descriptors, including the recently proposed solute excess volume. ${ }^{36}$

Structural information on the binding mode of halogenated benzotriazoles to CK2 is complex. Structures of TBBt bound to the $\alpha$-subunit of maize $\mathrm{CK} 2(\operatorname{mCK} 2 \alpha)^{38}$ and human $\mathrm{CDK} 2 /$ cyclin A kinase ${ }^{39}$ have been reported. A structure of hCK2 $\alpha$ in complex with $3-\left(4,5,6,7-\mathrm{Br}_{4}-1 H\right.$-benzotriazol-1yl)propan-1-ol, which can be considered a nonionizable TBBt analogue, has also been determined. ${ }^{40}$ The structures of $\mathrm{mCK} 2 \alpha$ in complex with $\mathrm{TBBi}^{41}$ and pentabromoindazole ${ }^{42}$ that differ in the nitrogen configuration in the heterocyclic ring are known. Structures of benzotriazole compounds with other bromination patterns bound in the $\mathrm{hCK} 2 \alpha$ pocket are to our knowledge not available. However, the structures of 5,6bromobenzotriazole $\left(5,6-\mathrm{Br}_{2} \mathrm{Bt}\right)$ in complex with $\mathrm{mCK} 2 \alpha^{36}$ and of the chloro analogue of $5,6-\mathrm{Br}_{2} \mathrm{Bt}\left(5,6-\mathrm{Cl}_{2}-1-b\right.$-Dribofuranosyl-benzimidazole, DRB) bound to hCK $2 \alpha^{43}$ have been published.

Several hundred halogenated ligands have already been identified in publicly available protein kinase structures. ${ }^{44}$ Although they mainly bind to the ATP-binding site, their poses are significantly different. ${ }^{39,41,44,45}$ For halogenated benzotriazoles and benzimidazoles, prior studies have indicated that the binding mode is determined by a tug of war between a hydrogen bond/salt bridge and halogen bonding. ${ }^{41}$ The estimation of the free energy of a halogen bond in real biological systems is still controversial since the introduction of a halogen atom $(\mathrm{Cl}, \mathrm{Br}, \mathrm{I})$ into a ligand molecule affects many of its physicochemical properties, including hydrophobicity, polarity, and $\mathrm{p} K_{\mathrm{a}}$ of nearby ionizable groups. Our recent thermodynamic studies on binding of variously brominated benzotriazoles to hCK $2 \alpha$ have supported the concept of the predominant contribution of electrostatic interactions and ligand (de)solvation to the free energy of binding. ${ }^{33}$

Here, we present a set of crystal structures of eight halogenated benzotriazoles in complex with a catalytic subunit of human protein kinase CK2. One of the nine studied ligands, $4,5,7-\mathrm{Br}_{3} \mathrm{Bt}$, was not reliably detected in the hCK2 $\alpha$ ATPbinding pocket in the cocrystal. The structural analysis is accompanied by thermal denaturation and calorimetric data that show an increase of ligand affinity with bromo substitution. The thermodynamic data also indicate a decrease of isobaric heat capacity upon ligand binding, attributable to the hydrophobic contribution to complex formation.

\section{METHODS}

2.1. Reagents. Brominated benzotriazoles were obtained as described previously. ${ }^{33,46}$ The catalytic domain of human protein kinase (hCK2 $\alpha$ ) was expressed and purified according to the published procedure. ${ }^{33}$ Protein sample homogeneity was confirmed by gel electrophoresis. The thermal profile of 
Table 1. Data Collection and Refinement Statistics

\begin{tabular}{|c|c|c|c|c|c|c|c|c|}
\hline data collection & $\begin{array}{c}\mathrm{hCK} 2 \alpha-4- \\
\mathrm{BrBt}\end{array}$ & $\begin{array}{c}\text { hCK } 2 \alpha-5- \\
\text { BrBt }\end{array}$ & $\begin{array}{c}\mathrm{hCK} 2 \alpha-4,5- \\
\mathrm{Br}_{2} \mathrm{Bt}\end{array}$ & $\begin{array}{c}\mathrm{hCK} 2 \alpha-4,6- \\
\mathrm{Br}_{2} \mathrm{Bt}\end{array}$ & $\begin{array}{c}\mathrm{hCK} 2 \alpha-4,7- \\
\mathrm{Br}_{2} \mathrm{Bt}\end{array}$ & $\begin{array}{c}\mathrm{hCK} 2 \alpha-5,6- \\
\mathrm{Br}_{2} \mathrm{Bt}\end{array}$ & $\begin{array}{c}\mathrm{hCK} 2 \alpha-4,5,6- \\
\mathrm{Br}_{3} \mathrm{Bt}\end{array}$ & $\begin{array}{c}\mathrm{hCK} 2 \alpha-\mathrm{TBBt} \\
\left(4,5,6,7-\mathrm{Br}_{4} \mathrm{Bt}\right)\end{array}$ \\
\hline \multicolumn{8}{|l|}{ cell dimensions } & $P 4_{2} 2_{1} 2$ \\
\hline$a, b(\AA)$ & 128.5 & 128.8 & 129.3 & 128.0 & 128.3 & 127.2 & 129.0 & 127.4 \\
\hline$c(\AA)$ & 61.1 & 60.9 & 60.7 & 61.1 & 61.2 & 60.9 & 61.1 & 61.0 \\
\hline wavelength ( & 0.9794 & 0.9116 & 0.9794 & 0.9794 & 0.9116 & 0.9117 & 0.9116 & 0.9116 \\
\hline resolution $(\AA)$ & 1.73 & 1.67 & 1.81 & 1.46 & 1.64 & 1.93 & 1.69 & 1.88 \\
\hline lowest shell & $(44.3-5.15)$ & $(36.5-4.98)$ & $(36.5-5.38)$ & $(44.2-4.36)$ & $(44.3-4.89)$ & $(36.2-5.72)$ & $(44.4-5.03)$ & $(45.0-5.60)$ \\
\hline highest shell & $(1.83-1.73)$ & $(1.77-1.67)$ & $(1.92-1.81)$ & $(1.55-1.46)$ & $(1.74-1.64)$ & $(2.04-1.93)$ & $(1.79-1.69)$ & $(1.99-1.88)$ \\
\hline$R_{\text {meas }}(\%)^{a}$ & $\begin{array}{r}5.6(3.2) \\
193.2)\end{array}$ & $\begin{array}{r}9.1(5.0 \\
128.7)\end{array}$ & $\begin{array}{c}7.8(5.4 \\
104.4)\end{array}$ & $\begin{array}{r}5.3(3.9 \\
200.3)\end{array}$ & $\begin{array}{r}6.6(3.5 \\
191.0)\end{array}$ & $\begin{array}{c}14.2(3.8 \\
170.3)\end{array}$ & $\begin{array}{c}10.2(5.4 \\
166.1)\end{array}$ & $9.1(5.5,127.8)$ \\
\hline $\mathrm{CC} 1 / 2^{a}$ & $\begin{array}{c}100(99.9 \\
83.1)\end{array}$ & $\begin{array}{c}99.9(99.9 \\
85.6)\end{array}$ & $\begin{array}{c}99.9(99.8 \\
93.8)\end{array}$ & $\begin{array}{c}100(99.9 \\
72.6)\end{array}$ & $\begin{array}{c}100(100 \\
77.9)\end{array}$ & $\begin{array}{c}99.9(100 \\
80.7)\end{array}$ & $\begin{array}{c}99.9(99.9 \\
83.1)\end{array}$ & $99.9(99.9,85.1)$ \\
\hline$I / \sigma I^{a}$ & $\begin{array}{c}32.1(103.5 \\
1.94)\end{array}$ & $\begin{array}{c}20.6(53.8 \\
2.11)\end{array}$ & $\begin{array}{c}22.8(55.6 \\
2.12)\end{array}$ & $\begin{array}{c}32.1(90.1 \\
1.99)\end{array}$ & $\begin{array}{c}29.0(85.31 \\
2.1)\end{array}$ & $\begin{array}{c}22.7(82.5 \\
1.98)\end{array}$ & $\begin{array}{c}19.5(52.3 \\
1.96)\end{array}$ & $20.6(51.1,2.07)$ \\
\hline completeness $(\%)^{a}$ & $\begin{array}{c}99.0(99.6 \\
98.6)\end{array}$ & $\begin{array}{c}99.2(99.4 \\
95.5)\end{array}$ & $\begin{array}{c}98.9(99.3 \\
93.6)\end{array}$ & $\begin{array}{c}99.9(99.8 \\
99.6)\end{array}$ & $\begin{array}{c}98.3(97.4 \\
96.7)\end{array}$ & $\begin{array}{c}99.9(99.4 \\
99.5)\end{array}$ & $\begin{array}{c}97.9(99.6 \\
86.7)\end{array}$ & $99.6(99.7,97.6)$ \\
\hline multiplicity $^{a}$ & $\begin{array}{c}24.6(20.6 \\
20.7)\end{array}$ & $\begin{array}{c}24.4(22.2 \\
22.2)\end{array}$ & $\begin{array}{c}24.7(21.8 \\
23.7)\end{array}$ & $\begin{array}{c}25.1(21.9 \\
22.4)\end{array}$ & $\begin{array}{c}26.2(22.8 \\
26.4)\end{array}$ & $\begin{array}{c}26.2(23.3 \\
25.4)\end{array}$ & $\begin{array}{l}25.1(22.1 \\
24.3)\end{array}$ & $24.8(21.3,23.6)$ \\
\hline $\begin{array}{l}\text { no. reflections } \\
\text { refinement }\end{array}$ & 53681 & 59111 & 46962 & 88427 & 62198 & 38226 & 57252 & 41198 \\
\hline$R_{\text {work }}$ & 16.02 & 14.44 & 16.39 & 15.39 & 14.86 & 15.33 & 14.88 & 15.97 \\
\hline$R_{\text {free }}$ & 18.73 & 17.26 & 18.45 & 17.27 & 17.76 & 18.86 & 17.13 & 18.70 \\
\hline no. atoms ${ }^{b}$ & 3728 & 4076 & 3643 & 4152 & 3795 & 3855 & 3995 & 3799 \\
\hline protein & 3244 & 3435 & 3196 & 3517 & 3233 & 3299 & 3405 & 3283 \\
\hline ligand & 10 & 30 & 33 & 33 & 33 & 11 & 36 & 65 \\
\hline other & 474 & 610 & 414 & 597 & 529 & 545 & 554 & 452 \\
\hline $\begin{array}{l}\text { bond lengths rmsd } \\
(\AA)\end{array}$ & 0.007 & 0.008 & 0.007 & 0.006 & 0.007 & 0.005 & 0.006 & 0.005 \\
\hline $\begin{array}{c}\text { bond angles rmsd } \\
\text { (deg) }\end{array}$ & 1.40 & 1.44 & 1.39 & 133 & 1.36 & 1.27 & 1.35 & 1.25 \\
\hline \multicolumn{9}{|l|}{ Ramachandran } \\
\hline allowed (\%) & 100 & 99.7 & 100 & 100 & 100 & 100 & 100 & 100 \\
\hline favored (\%) & 96.4 & 96.7 & 96.8 & 97.3 & 96.7 & 96.4 & 95.8 & 96.7 \\
\hline $\begin{array}{l}\text { mol probity clash } \\
\text { score }\end{array}$ & 2.2 & 3.9 & 3.8 & 3.1 & 2.5 & 2.3 & 3.8 & 3.6 \\
\hline PDB code & 6TLW & 6TLV & 6TLU & 6TLS & 6TLR & 6TLP & $6 \mathrm{TLO}$ & 6TLL \\
\hline
\end{tabular}

fluorescence-monitored protein stability was used prior to the calorimetric experiment as a descriptor of the proper folding of the enzyme. ${ }^{34}$

2.2. Crystallization. $\mathrm{hCK} 2 \alpha$ was stored at $-80{ }^{\circ} \mathrm{C}$ in glycerol solution prior to use. Before crystallization, the protein was dialyzed against buffer A (25 mM Tris- $\mathrm{HCl}$ pH 8.5, $0.5 \mathrm{M}$ $\mathrm{NaCl}, 5 \mathrm{mM} \beta$-mercaptoethanol). The protein sample was then concentrated on VivaSpin $50000 \mathrm{MWCO}$ to $4-8 \mathrm{mg} / \mathrm{mL}$ and mixed with a $0.25 \mathrm{M}$ solution of a ligand in DMSO in 1:24 molar ratio. Crystals were grown in sitting drops by the vapor diffusion method. The $2 \mu \mathrm{L}$ drops were set up manually using the 1:1 mixture of protein-ligand complex solution and crystallization buffer (0.1 M sodium HEPES/MOPS buffer $\mathrm{pH}$ $7.5,20 \mathrm{mM}$ sodium formate, $20 \mathrm{mM}$ ammonium acetate, 20 $\mathrm{mM}$ sodium citrate tribasic dihydrate, $20 \mathrm{mM}$ sodium potassium tartrate tetrahydrate, $20 \mathrm{mM}$ sodium oxamate, 20\% poly(ethylene glycol) 550 monomethyl ester, $10 \%$ poly(ethylene glycol) 20000). Crystals could be flashcryocooled without an additional cryoprotection step. Diffraction data were collected at the P14 beamline of EMBL/DESY (Hamburg, Germany), P11 beamline of DESY (Hamburg, Germany), and MX 14.1 beamline of BESSY (Berlin, Germany). Preliminary diffraction experiments were also carried out at the XRD1 beamline of ELETTRA (Trieste, Italy).

2.3. Structure Determination. The structures were readily solved by molecular replacement with the help of the MolRep program ${ }^{47}$ using the structure of the human holoenzyme as a model (PDB code $3 \mathrm{WAR}^{48}$ ). Subsequently,

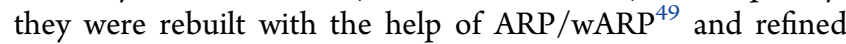
with the REFMAC program. ${ }^{50}$ In the cases of multiple noteasily resolvable ligand poses, the position of the ligands was confirmed using anomalous difference maps generated with the phases obtained from the Fourier transformation of the hCK $2 \alpha$ structures with the ligands omitted. The ligand constraints were generated with the PRODRG server. ${ }^{51}$ Since some of the crystals showed signs of weakly broken symmetry and could only be integrated with a unit cell two times larger than that observed in the other data, the $R_{\text {free }}$ reflections were selected in thin resolution shells. Data collection and refinement statistics are summarized in Table 1 . The refined models and the corresponding structure factors were deposited in the PDB with the accession codes stated in the table.

2.4. Surface Area Calculations. The solvent accessible surface changes were estimated with the Yasara Structure package (www.yasara.com). All low-mass molecules other than 
ligands placed at the hCK2 $\alpha$ ATP-binding site were removed prior to the calculations. The polar surface included all nitrogen and oxygen atoms together with their associated hydrogens, while the nonpolar one covered all remaining atoms with the exception of bromines, which were treated separately. The change of solvent accessible surface upon complex formation ( $\triangle \mathrm{ASA})$ was calculated as the difference between the surface of the complex and the sum of the surfaces of the ligand and the free protein calculated for crystal structures. The $\triangle \mathrm{ASA}$ values were estimated separately for each alternative position of the ligand and/or enzyme conformation and then averaged using occupancies as weights with RMSE values assigned as their inaccuracies.

2.5. Low-Volume Differential Scanning Fluorimetry (nanoDSF). The assay was carried out in $25 \mathrm{mM}$ Tris- $\mathrm{HCl}$ $(\mathrm{pH} 7.5,0.5 \mathrm{M} \mathrm{NaCl})$ buffer with the protein and ligands concentration preserved constant at 2.5 and $25 \mu \mathrm{M}$, respectively. The samples were loaded into nanoDSF grade Standard Capillaries (NanoTemper Technologies) and analyzed using the Prometheus NT.48 nanoDSF device (NanoTemper Technologies). Thermal unfolding of the protein was monitored using a linear thermal ramp $\left(1^{\circ} \mathrm{C} \cdot \mathrm{min}^{-1} ; 20-80\right.$ ${ }^{\circ} \mathrm{C}$ ) with an excitation power of $30 \%$. All numerical models were globally fitted to the experimental data, assuming a twostate cooperative transition at $T_{\mathrm{m}}$, using the Marquardt algorithm $^{52}$ implemented in the Origin 2019 package (OriginLab, Northampton, MA; www.originlab.com) according to the following equations.

$$
\begin{aligned}
& F(T)=F_{\text {fold }}(T) \cdot p_{\text {fold }}(T)+F_{\text {unf }}(T) \cdot\left(1-p_{\text {fold }}(T)\right) \\
& p_{\text {fold }}(T)=1 /(1+\exp (\Delta G(T) / R T)) \\
& \Delta G(T)=\left[\Delta H_{T \mathrm{~m}}+\Delta C_{p} \cdot\left(T-T_{\mathrm{m}}\right)\right] \\
& -T \cdot\left[\Delta S_{T \mathrm{~m}}+\Delta C_{p} \cdot \ln \left(T / T_{\mathrm{m}}\right)\right] \\
& 0=\Delta G\left(T_{\mathrm{m}}\right)=\Delta H_{T \mathrm{~m}}-\Delta S_{T \mathrm{~m}} \cdot T_{\mathrm{m}}
\end{aligned}
$$

where $F(T)$ is the observed fluorescence signal, $F_{\text {fold }}(T)$ and $F_{\text {unf }}(T)$ are the low- and high-temperature linear asymptotes of $F(T) ; \Delta G(T)$ is the free energy of unfolding at a given temperature; $T_{\mathrm{m}}$ is the middle-point transition temperature; $\Delta H_{T \mathrm{~m}}$ and $\Delta S_{T \mathrm{~m}}$ are the heat and entropy of the unfolding at $T_{\mathrm{m}}\left(\Delta G\left(T_{\mathrm{m}}\right)=0\right)$; and $\Delta C_{p}$ is the heat capacity change upon the protein unfolding. ${ }^{53}$

2.6. Isothermal Titration Calorimetry (ITC). ITC measurements were carried out using the MicroCal iTC200 (Malvern) calorimeter. The hCK $2 \alpha$ samples were diluted to the required protein concentration with the $25 \mathrm{mM}$ Tris- $\mathrm{HCl}$ $\mathrm{pH} 8$ buffer containing $0.5 \mathrm{M} \mathrm{NaCl}$. Stock ligand solutions were diluted with the appropriate DMSO volume prior to mixing with the buffer to obtain the required ligand concentration and a final DMSO content of $1 \%$. Due to the limited solubility of halogenated benzotriazoles, all titration experiments were performed in the reverse mode, in which buffered ligand solution was placed in the calorimetric cell and titrated with the protein solution. ${ }^{35}$ The resulting thermograms were preprocessed with the supplied MicroCal ITC-ORIGIN Analysis Software, and the thermodynamic parameters were further estimated at each temperature using previously reported customized procedures ${ }^{54,55}$ reimplemented in the Origin 2019 package (OriginLab, Northampton, MA; www. originlab.com).
For the three strongest ligands, the titration experiments were additionally performed using the NanoITC calorimeter (TA Instruments). We have found that heats of binding $(\Delta H)$ estimated using the two calorimeters differ significantly. To deal with these discrepancies, we have studied the reference reaction of 18 -crown- 6 with $\mathrm{BaCl}_{2}$ recommended by IUPAC (Table S1).

The dissociation constant was close to the reference value for both calorimeters, but the enthalpy for binding was consistent with the IUPAC value only for the MicroCal iTC ${ }_{200}$, while for the NanoITC it was underestimated by approximately $12 \%$. Interestingly, a similar trend was reported by others for the titration of TRIS with $\mathrm{HNO}_{3}{ }^{56}$ The inspection of the raw data, together with the technical specification and hardware-specific baseline determination algorithms, clearly suggests that the thermodynamic data from the MicroCal $\mathrm{iTC}_{200}$ are more reliable. Only these data were analyzed further, but for completeness we also report thermodynamic parameters determined with a NanoITC calorimeter (Table S2). In all experiments the maximum ligand concentration of $10 \mu \mathrm{M}$ was used to minimize a possible contribution of the secondary binding site.

2.7. Density Measurements. Partial molar volumes were estimated with a density meter Anton Paar DMA $5000 \mathrm{M}$ at 20,25 , and $30{ }^{\circ} \mathrm{C}$ from the concentration-density dependency for compounds dissolved in $50 \mathrm{mM}$ phosphate buffer ( $\mathrm{pH} 11)$. The experimental procedure and the data analysis method were described previously. ${ }^{36,57,58}$ The partial molar volume at $25{ }^{\circ} \mathrm{C}\left(V_{2}^{0}\right)$ and thermal volumetric expansivity of the solute $\left(\alpha_{2}{ }^{0}=\partial V_{2}{ }^{0} / \partial T\right)$ were estimated globally from two independent dilution series. The density of pure solvent $\left(d_{0}\right)$ was extrapolated individually for each experimental condition (i.e., temperature and buffer preparation). The change of $d_{0}$ with temperature was further used to determine thermal volumetric expansivity coefficient of the bulk buffer according to the formula $\alpha_{0}=-\left(\partial \mathrm{d}_{0} / \partial T\right) / d_{0}$.

\section{RESULTS}

3.1. Structural Analysis of hCK2 $\alpha$-Bromobenzotriazole Complexes. To verify the binding mode of brominated benzotriazoles to human $\mathrm{CK} 2 \alpha$, crystals of the enzyme in complex with eight differently halogenated ligands were obtained (covering all but one combination of benzyl ring modifications) (Table 1). Cocrystallization with the ninth compound $\left(4,5,7-\mathrm{Br}_{3} \mathrm{Bt}\right)$ was attempted, but the ligand was not detected in the ATP-binding pocket of the enzyme. The crystals belonged to the $P 4_{2} 2_{1} 2$ tetragonal space group and contained a single molecule of the complex in the asymmetric unit. Probably due to the crystallization conditions, $\mathrm{Mg}^{2+}$ ions were absent from the active site of the kinase, with surprisingly little effect on the protein conformation including residues directly involved in the metal chelation. All complexes presented in this work show the hallmarks of the active CK2 form (Figure S1). In particular, the C-helix (residues 74-89) of the N-terminal lobe and the activation loop (residues 182190) are precisely in the expected positions. However, the complex structures differ notably from the reference conformation of the active kinase by the disorder of the Ploop (glycine-rich loop, residues 45-49). In the presence of the cosubstrate ATP, the P-loop wraps over the triphosphate and is fairly ordered. In its absence, as in our structures, it lacks the anchor and becomes disordered (Figure S1). 

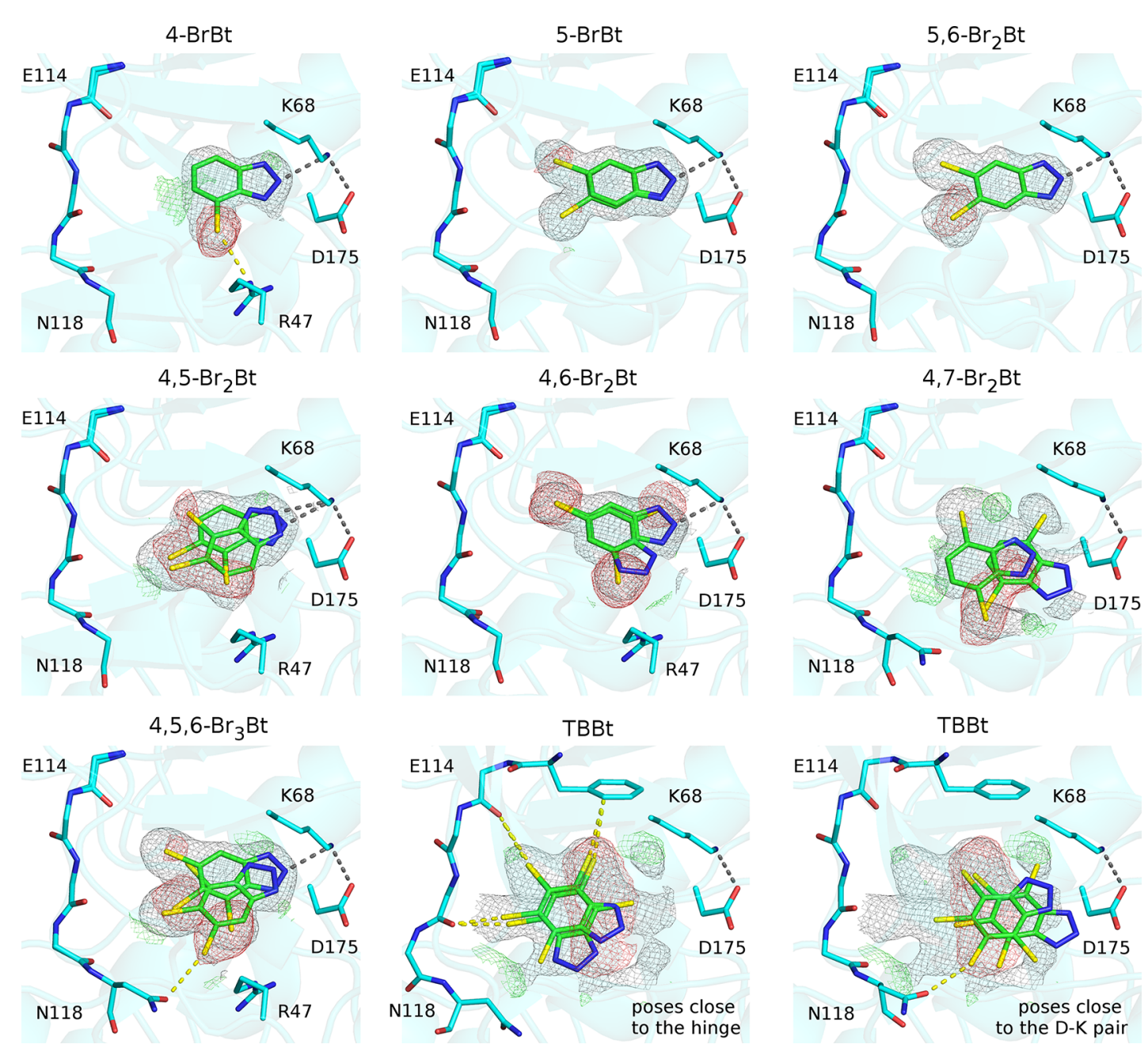

Figure 1. Ligand-binding pocket of human $\mathrm{CK} 2 \alpha$ in complex with eight bromobenzotriazole inhibitors. Protein-ligand contacts including hydrogen bonds are indicated in gray and halogen interactions in yellow. The side chains of most hinge region residues and the main chains of R47, K68, and D175 are omitted for clarity. Composite omit (gray, contoured at $1 \mathrm{rmsd}$ ) and $F_{0}-F_{\mathrm{c}}$ (red/green contoured at \pm 3 rmsd) maps are shown for the ligand. The last two panels depict four poses observed for TBBt. With the exception of the compounds with 4,7-substitution, the bromobenzotriazoles can adopt a canonical pose. In many cases, particularly for the highly substituted benzotriazoles, multiple poses are observed.

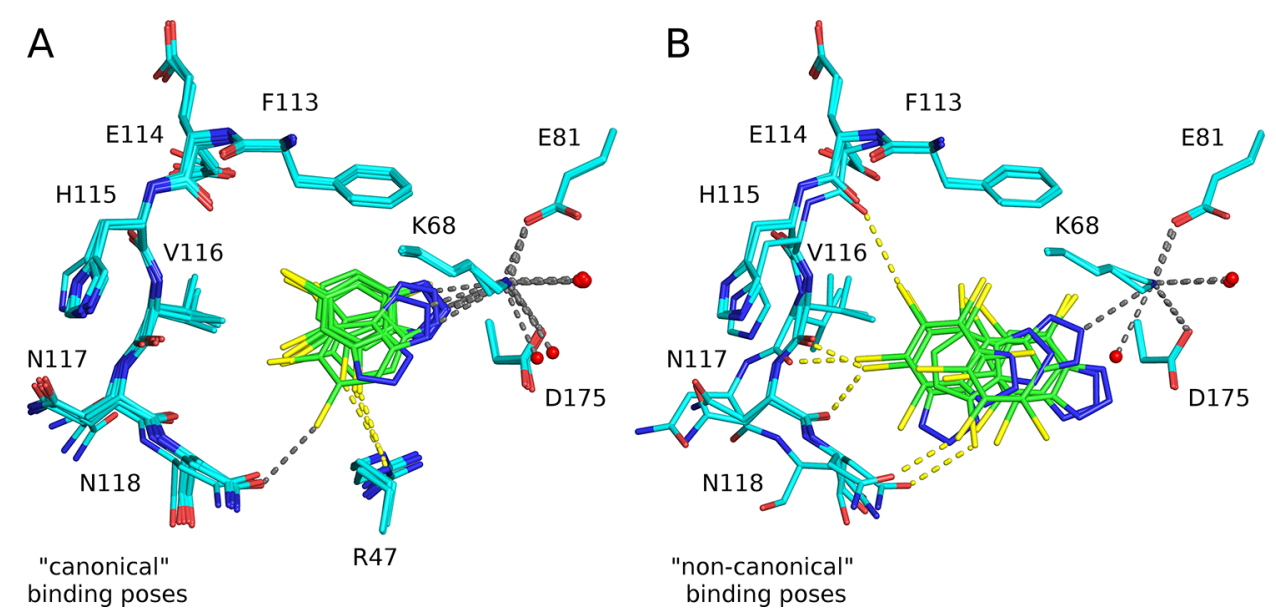

Figure 2. Binding poses of bromobenzotriazoles in the hCK2 $\alpha$ ATP-binding pocket. For the canonical pose (A) hydrogen bonding or salt bridge formation is chosen over halogen bonding, while for some noncanonical poses (B) halogen-bonding interactions are formed, at the expense of the hydrogen bond or salt bridge.

All bound bromobenzotriazoles were located in the ATPbinding pocket (Figure 1). The ligand-binding modes were deduced from the composite omit maps and independently confirmed by the analysis of the crystallographic anomalous signal from the bromine atoms (Figure S3). In all eight structures, we have detected the signal from the bromine atoms 
Table 2. Thermal Stability of hCK2 $\alpha$ in Complex with Nine Bromobenzotriazole Compounds Determined with FluorescenceMonitored Thermal Denaturation (nanoDSF) at $\mathrm{pH} 7.5$ and $8.0^{33}$ and Literature Data for the Inhibitory Activity of the Studied Ligands ${ }^{32}$

\begin{tabular}{|c|c|c|c|c|}
\hline ligand & $T_{\mathrm{m}}\left({ }^{\circ} \mathrm{C}\right)$ at $\mathrm{pH} 7.5$ & $\Delta T_{\mathrm{m}}\left({ }^{\circ} \mathrm{C}\right)$ at $\mathrm{pH} 7.5$ & $\Delta T_{\mathrm{m}}\left({ }^{\circ} \mathrm{C}\right)$ at $\mathrm{pH} 8^{33}$ & $\mathrm{IC}_{50}(\mu \mathrm{M})$ at $\mathrm{pH} 7.5^{32}$ \\
\hline apo & $45.19 \pm 0.03$ & - & - & - \\
\hline $4-\mathrm{BrBt}$ & $45.92 \pm 0.05$ & $0.7 \pm 0.1$ & $0.5 \pm 0.1$ & $119 \pm 10$ \\
\hline $5-\mathrm{BrBt}$ & $47.17 \pm 0.02$ & $2.0 \pm 0.1$ & $1.8 \pm 0.1$ & $26 \pm 3$ \\
\hline $4,5-\mathrm{Br} 2 \mathrm{Bt}$ & $49.55 \pm 0.05$ & $4.4 \pm 0.1$ & $3.5 \pm 0.1$ & $10.6 \pm 0.9$ \\
\hline $4,6-\mathrm{Br}_{2} \mathrm{Bt}$ & $49.21 \pm 0.04$ & $4.0 \pm 0.1$ & $3.6 \pm 0.1$ & $10.0 \pm 2.2$ \\
\hline $4,7-\mathrm{Br}_{2} \mathrm{Bt}$ & $47.15 \pm 0.03$ & $2.0 \pm 0.1$ & $0.9 \pm 0.1$ & $72 \pm 11$ \\
\hline $5,6-\mathrm{Br}_{2} \mathrm{Bt}$ & $52.96 \pm 0.05$ & $7.8 \pm 0.1$ & $7.4 \pm 0.1$ & $0.56 \pm 0.02$ \\
\hline $4,5,6-\mathrm{Br}_{3} \mathrm{Bt}$ & $53.84 \pm 0.04$ & $8.7 \pm 0.1$ & $8.4 \pm 0.1$ & $0.38 \pm 0.02$ \\
\hline $4,5,7-\mathrm{Br}_{3} \mathrm{Bt}$ & $49.81 \pm 0.07$ & $4.6 \pm 0.1$ & $5.2 \pm 0.1$ & $5.8 \pm 0.9$ \\
\hline $4,5,6,7-\mathrm{Br}_{4} \mathrm{Bt}(\mathrm{TBBt})$ & $55.11 \pm 0.03$ & $9.9 \pm 0.1$ & $9.0 \pm 0.1$ & $0.27 \pm 0.07$ \\
\hline
\end{tabular}

\section{A}
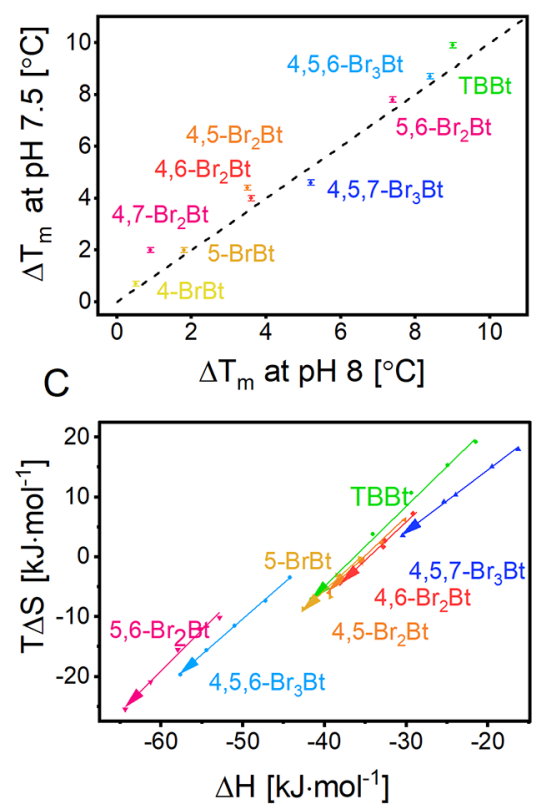

B

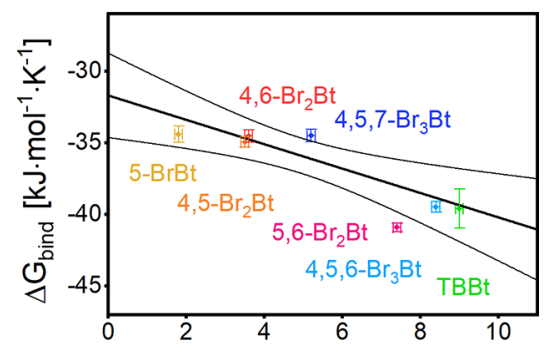

D $\quad \Delta \mathrm{T}_{\mathrm{m}}$ at $\mathrm{pH} 8\left[{ }^{\circ} \mathrm{C}\right]$

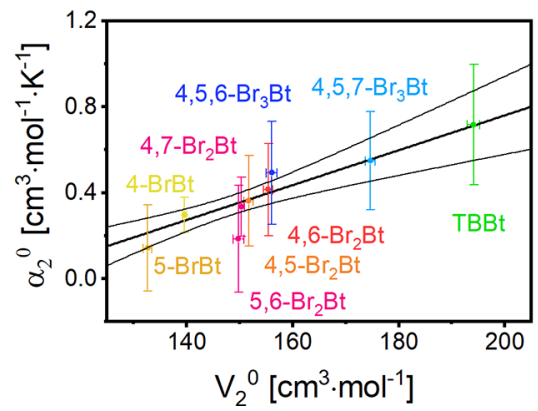

Figure 3. Thermodynamics of the hCK $2 \alpha$-bromobenzotriazole interaction. (A) Thermal unfolding of hCK $2 \alpha$ complexes was monitored by nanoDSF at $\mathrm{pH}$ 7.5 and 8.0. $\Delta T_{\mathrm{m}}$ values indicate the difference of the unfolding temperature in the presence and absence of a ligand. The dashed line shows the expectation for no $\mathrm{pH}$ dependence. The more highly substituted bromobenzotriazoles stabilize the protein more strongly, indicating tighter binding. (B) Correlation of the free energies of binding (at $25{ }^{\circ} \mathrm{C}$ ) with hCK2 $\alpha$ stabilization. Thin lines represent $95 \%$ confidence bands for the fitted line. (C) Entropy-enthalpy compensation with respect to temperature. The arrows mark the general trend in the temperature range from 15 to $35^{\circ} \mathrm{C}$. Entropic $\Delta S$ and enthalpic $-\Delta H$ contributions decrease and increase strongly with temperature, respectively. The two effects mostly compensate for the free energy of binding $\Delta G=\Delta H-T \Delta S$. Figures S6 and S7 show detailed trends observed for the particular ligands. (D) Correlation of the solute thermal expansivity with the partial molar volume of ligands.

even if the data were collected away from the absorption edge. In some cases, additional binding sites on the surface were observed, including a previously defined site located at the interface of $\alpha$ - and $\beta$-domains (Figure S2). ${ }^{43}$ Interestingly, a signature of a weak secondary binding site was also recently reported for several bromobenzotriazoles using a combination of MST and ITC. ${ }^{35}$

The binding modes of bromobenzotriazoles in the hCK $2 \alpha$ ATP-binding pocket are best described by dividing them into one "canonical" and several "noncanonical" ones. The canonical binding mode is observed for 4-BrBt, $5-\mathrm{BrBt}$, 4,5$\mathrm{Br}_{2} \mathrm{Bt}$, 4,6- $\mathrm{Br}_{2} \mathrm{Bt}$, 5,6- $\mathrm{Br}_{2} \mathrm{Bt}$, and 4,5,6- $\mathrm{Br}_{3} \mathrm{Bt}$ (Figure 2). The benzotriazoles in this group, except for $5-\mathrm{BrBt}$ and $4,5-\mathrm{Br}_{2} \mathrm{Bt}$, bind in one predominant pose, similar for all of them. Additional binding modes are also observed for $4,6-\mathrm{Br}_{2} \mathrm{Bt}$ and $4,5,6-\mathrm{Br}_{3} \mathrm{Bt}$, but they are clearly weaker than the dominant one.
The binding mode of 5-BrBt in the crystal structure resembles that of 5,6-bromobenzotriazole. However, the ligand is observed in two alternative positions. The single 5-bromo substituent is located more or less deep in the ATP-binding pocket and corresponds to either the 5- or 6-bromo substituent of $5,6-\mathrm{Br}_{2} \mathrm{Bt}$. The identity of the $5-\mathrm{BrBt}$ is unambiguously confirmed by the secondary binding site in which only one ligand pose is observed. For $4,5-\mathrm{Br}_{2} \mathrm{Bt}$, one of the binding modes is similar to the canonical one, and the second one is $180^{\circ}$ rotated, so that the positions of the 5-bromo substituent and the N8 nitrogen are roughly preserved but the ligand is flipped.

The canonical binding pose of bromobenzotriazoles in the hCK $2 \alpha$-binding pocket orients the triazole toward the active site lysine (K68) and the phenyl ring toward the hinge region. Depending on the charge states of the lysine and the ligand in 
Table 3. Free Energy of Binding at $25^{\circ} \mathrm{C}\left(\Delta G_{\text {bind }}\right)$ and Heat Capacity Changes $\left(\Delta C_{p, \text { bind }}\right)$ Associated with Bromobenzotriazole Interaction with hCK2 $\alpha$ Determined at $\mathrm{pH} 8$ with the Aid of Isothermal Titration Calorimetry (ITC)

\begin{tabular}{|c|c|c|c|c|c|c|c|}
\hline ligand & $\Delta G_{\text {bind }}\left(\mathrm{kJ} \cdot \mathrm{mol}^{-1}\right)$ & $\Delta C_{p, \text { bind }}\left(\mathrm{kJ} \cdot \mathrm{mol}^{-1} \cdot \mathrm{K}^{-1}\right)$ & $\Delta \mathrm{ASA}\left(\AA^{2}\right)$ & $\log P^{36}$ & $\alpha_{2}^{0}\left(\mathrm{~cm}^{3} \cdot \mathrm{mol}^{-1} \cdot \mathrm{K}^{-1}\right)$ & $V_{2}^{0}\left(\mathrm{~cm}^{3} \cdot \mathrm{mol}^{-1}\right)$ & $\log (\tau)^{37}$ \\
\hline 4-BrBt & & & $370 \pm 2$ & 1.72 & $0.30 \pm 0.08$ & $139.6 \pm 0.3$ & -0.65 \\
\hline $5-\mathrm{BrBt}$ & $-34.4 \pm 0.6$ & $-0.28 \pm 0.13$ & $376 \pm 5$ & 1.73 & $0.14 \pm 0.20$ & $132.7 \pm 0.8$ & -0.41 \\
\hline $4,5-\mathrm{Br}_{2} \mathrm{Bt}$ & $-34.9 \pm 0.4$ & $-0.43 \pm 0.05$ & $404 \pm 3$ & 2.34 & $0.36 \pm 0.21$ & $151.7 \pm 0.9$ & -0.39 \\
\hline $4,6-\mathrm{Br}_{2} \mathrm{Bt}$ & $-34.5 \pm 0.4$ & $-0.44 \pm 0.06$ & $391 \pm 6$ & 2.37 & $0.41 \pm 0.21$ & $155.4 \pm 0.9$ & -0.38 \\
\hline $4,7-\mathrm{Br}_{2} \mathrm{Bt}$ & & & $419 \pm 1$ & 2.37 & $0.19 \pm 0.25$ & $149.8 \pm 1.0$ & -0.55 \\
\hline $5,6-\mathrm{Br}_{2} \mathrm{Bt}$ & $-40.9 \pm 0.3$ & $-0.59 \pm 0.07$ & $395 \pm 1$ & 2.36 & $0.33 \pm 0.14$ & $150.0 \pm 0.6$ & -0.30 \\
\hline $4,5,6-\mathrm{Br}_{3} \mathrm{Bt}$ & $-39.5 \pm 0.4$ & $-0.68 \pm 0.06$ & $428 \pm 4$ & 2.96 & $0.49 \pm 0.24$ & $156.0 \pm 1.0$ & -0.20 \\
\hline $4,5,7-\mathrm{Br}_{3} \mathrm{Bt}$ & $-34.5 \pm 0.4$ & $-0.68 \pm 0.07$ & & 2.98 & $0.55 \pm 0.23$ & $174.7 \pm 0.9$ & -0.22 \\
\hline $4,5,6,7-\mathrm{Br}_{4} \mathrm{Bt}$ & $-39.6 \pm 1.4$ & $-0.97 \pm 0.10$ & $479 \pm 24$ & 3.58 & $0.72 \pm 0.28$ & $194.1 \pm 1.1$ & -0.00 \\
\hline \multirow{2}{*}{\multicolumn{3}{|c|}{ Pearson's $r$ with $\Delta C_{p \text {,bind }}$}} & 0.933 & 0.941 & 0.930 & - & 0.983 \\
\hline & & & $(0.980)^{a}$ & $(0.994)^{a}$ & $0.949^{b 1} / 0.980^{b 2}$ & $0.999^{b 1} / 0.997^{b 2}$ & \\
\hline
\end{tabular}

${ }^{a}$ Pearson's $r$ with $\Delta C_{p, \text { bind }}$ with values for ligands with fractional dissociation $<0.95$ (5-BrBt and 5,6-Br ${ }_{2} \mathrm{Bt}$ ) excluded. ${ }^{b}$ Ligands were divided into two groups: ${ }^{b 1}$ the ones with both C5 and C6 positions brominated and ${ }^{b 2}$ the remaining ones.

the pocket (highly brominated benzotriazoles are expected to be acidic), this binding pose creates the possibility for a hydrogen bond or a salt bridge with the side chain of K68. For the benzotriazoles with 5- and/or 6-bromo substituents, there is also a chance for the formation of one or two halogen bonds with carbonyl oxygen atoms of the kinase hinge region as the acceptors. Since the potential hydrogen (or salt bridge) and halogen-bonding partners are typically too distant to each other for both interaction types to occur simultaneously, a tug of war between them is set up. Not unexpectedly, this competition is resolved in favor of the hydrogen bond or salt bridge formation, judging from the distances in the crystal structures. In the cases where this is possible (for compounds with the 4-bromo substituent), the halogen bond may instead be formed with one of the conformers of R47 or N118. The arginine is anchored in the P-loop region that in these cases adopts at least two distinct conformations; the asparagine belongs to the hinge region.

The noncanonically binding bromobenzotriazole group is comprised of the compounds with both 4- and 7-bromo substituents present $\left(4,7-\mathrm{Br}_{2} \mathrm{Bt}\right.$ and $\left.\mathrm{TBBt}\right)$. Ligands from this group are pushed away from the pocket by the presence of the substituent in the "lateral" position. As a result, the hydrogen bond/salt bridge formation is more difficult, and the interaction is sometimes lost in favor of a halogen bond or optimized shape complementarity. The $4,7-\mathrm{Br}_{2} \mathrm{Bt}$ ligand is bound in one dominant and one weaker mode. TBBt in turn, possibly due to its disclike shape, explores essentially the entire pocket, in multiple and not clearly separable poses. In some of the orientations, the benzotriazole is closer to the hinge region, so that halogen bonds may be formed. However, the lack of discrimination between different poses of this ligand in the CK $2 \alpha$ pocket suggests that the hydrophobic effect is the dominant driver for its binding.

3.2. Stabilization of hCK $2 \alpha$ by the Bromobenzotriazoles. Recent comprehensive thermodynamic ${ }^{33}$ and biochemical studies ${ }^{32}$ allowed us to rank bromobenzotriazole ligands in terms of their binding affinity to hCK $2 \alpha$. The results clearly demonstrated that a balance of hydrophobic and electrostatic interactions has predominant contribution to the binding affinity. ${ }^{32-34}$ The structures of hCK $2 \alpha$ complexes shown above as well as the published values of $\mathrm{IC}_{50}$ (Table 2) ${ }^{32}$ were determined at $\mathrm{pH}$ 7.5, while the previous thermodynamic studies were performed at $\mathrm{pH} 8.0 .^{33,35}$ This prompted us to measure the thermal stabilities of $\mathrm{hCK} 2 \alpha$ and its complexes at
$\mathrm{pH} 7.5$ by fluorescence-monitored thermal denaturation (nanoDSF) (Table 2). The extent of ligand-induced hCK $2 \alpha$ stabilization was almost the same at both $\mathrm{pH}$ values (Figure $3 \mathrm{~A})$. It grew with the number of bromo substituents, with larger contributions from the modifications in 5 and 6 than 4 and 7 positions. We have previously shown that the dissociation constants determined for halogenated benzotriazoles, when converted according to the ATP concentration in the assay, perfectly reconstruct experimental $\mathrm{IC}_{50}$ values. ${ }^{33}$ Similarly, the ITC-derived binding affinities generally agreed with the inhibitory activities determined for the same ligands ${ }^{32}$ (Figure S4).

3.3. Calorimetric Analysis of the Bromobenzotriazole-hCK2 $\alpha$ Interaction. Thermodynamic parameters of the benzotriazole hCK $2 \alpha$ complex formation were measured on the MicroCal $\mathrm{iTC}_{200}$ (Malvern). All ligands could be analyzed, with the exception of two weakly binding ones $\left(4,7-\mathrm{Br}_{2} \mathrm{Bt}\right.$ and 4-BrBt). As expected, the calorimetric data confirmed the benzotriazoles with bromo substituents in the 5 and 6 positions ( $\mathrm{TBBt}, 4,5,6-\mathrm{Br}_{3} \mathrm{Bt}$ and $5,6-\mathrm{Br} \mathrm{r}_{2} \mathrm{Bt}$ ) as the strongest ligands. Tighter-binding ligands (more negative $\Delta G$ values) stabilized hCK $2 \alpha$ more strongly (Figure 3B). The binding of the three strongest ligands was additionally followed with a NanoITC calorimeter (Table S2, Figures S5 and S6).

We observed the usual entropy-enthalpy compensation. For all ligands, the free energies of binding $(\Delta G)$ were only weakly temperature-dependent, despite the strong temperature dependence of enthalpies $(\Delta H)$ and entropies $(\Delta S)$. At higher temperatures, the enthalpic contribution for ligand binding increased, while the entropic change became more unfavorable (Figure 3C, Figures S6 and S7). The slope values of the $T \Delta S(\Delta H)$ linear trend varied in the narrow range of $(0.99 \pm$ $0.03)$, clearly identifying that these two contributions compensate for the free energy of binding $(\Delta G=\Delta H-T \Delta S)$.

Entropy-enthalpy compensation was also observed for the number of bromo substituents in the ligand series. At fixed temperature, the binding enthalpy was less favorable for the more substituted brominated compounds. However, this effect was more than compensated by the increase in the entropic contribution. The strong entropic component can be interpreted as a signature of the hydrophobic effect: binding of the ligand releases more water molecules involved in the ligand solvation (and present in the ligand-binding cavity) into bulk solvent and thus increases the conformational freedom of these water molecules. 
Since the isobaric heat capacity of water solvating the hydrophobic surfaces is greater than for bulk water (despite the misleading description of this phenomenon as the "iceberg" effect ${ }^{59,60}$ ), the binding of hydrophobic ligands should be accompanied by a decrease in the isobaric heat capacity $\left(\Delta C_{p, \text { bind }}<0\right)$. Indeed, binding of brominated benzotriazoles was accompanied by negative $\Delta C_{p \text {,bind }}$ values (Table 3 ). The effect was more pronounced for highly substituted benzotriazole ligands than for less substituted ones. However, the $\Delta C_{p, \text { bind }}$ values did not follow the binding affinity. Instead, the ligands could be clustered into three groups, each with a different number of bromine atoms attached to the 5 and 6 position of the benzotriazole (Figure S8). All strong hCK2 $\alpha$ ligands $\left(K_{\mathrm{d}} \sim 0.1 \mu \mathrm{M} ; \Delta G_{\text {bind }} \sim-40 \mathrm{~kJ} \cdot \mathrm{mol}^{-1}\right)$ were substituted at both $\mathrm{C5}$ and $\mathrm{C} 6$; their weakly binding analogues $\left(K_{\mathrm{d}} \sim 1 \mu \mathrm{M} ; \Delta G_{\text {bind }} \sim-35 \mathrm{~kJ} \cdot \mathrm{mol}^{-1}\right)$ carried a single bromine at $\mathrm{C} 5 / \mathrm{C} 6$, while those unsubstituted at $\mathrm{C} 5 / \mathrm{C} 6$ virtually did not bind hCK $2 \alpha$.

3.4. Partial Molar Volume and Apparent Thermal Expansivity of Bromobenzotriazoles in Solution. According to the Lum, Chandler, and Weeks (LCW) theory, the hydrophobic interactions scale for solutes of subnanometer size with the volume of the molecule rather than its surface. ${ }^{61}$ We have recently proposed partial molar volume as the extensive parameter to describe both the solute volume and the solute-induced reorganization of the solvation shell. ${ }^{36,57,58,62,63}$ By analyzing density data at three temperatures $(20,25$, and 30 ${ }^{\circ} \mathrm{C}$ ), we could estimate the partial molar volume of the ligand $\left(V_{2}^{0}\right)$ and the bulk solvent density $\left(d_{0}(T)\right)$. We could further separate the thermal expansivity coefficient of the bulk solvent $\left(\alpha_{0}\right)$ and the apparent expansivity of the solute $\left(\alpha_{2}{ }^{0}\right)$. The latter parameter is comprised mainly of the thermal expansion effect of the hydration shell. The values of $\alpha_{0}$ fell within the narrow range of $(26.9 \pm 1.3) \times 10^{-5} \mathrm{~K}^{-1}$, which is close to the literature data for water $\left(25.72 \times 10^{-5} \mathrm{~K}^{-1}\right.$ at $\left.25^{\circ} \mathrm{C}\right) .{ }^{64}$ The density estimated at $25{ }^{\circ} \mathrm{C}$ for independent buffer preparations varied minutely in the range of $1.00399-1.00403 \mathrm{~g} \cdot \mathrm{cm}^{-3}$, significantly exceeding the water density at $25^{\circ} \mathrm{C}, 0.9970449 \mathrm{~g}$. $\mathrm{cm}^{-3}$. ${ }^{64}$ The volumetric data concerning solute $\left(V_{2}{ }^{0}, \alpha_{2}{ }^{0}\right)$ are listed in Table 3 . The solute thermal expansivity $\left(\alpha_{2}{ }^{0}\right)$, together with the change of isobaric heat capacity upon ligand binding $\left(\Delta C_{p, \text { bind }}\right)$, has already been associated with the properties of the solvation layer. ${ }^{65,66}$ Importantly, $\alpha_{2}{ }^{0}$ is proportional to the partial molar volume $V_{2}{ }^{0}$ (Figure $3 \mathrm{D}$ ). So, $V_{2}{ }^{0}$ may be another descriptor of hydrophobic interactions. Consequently, the volume-normalized solute expansivity coefficient $\left(\alpha=\alpha_{2}^{0} / V_{2}^{0}\right)$ is almost the same for all studied bromobenzotriazoles $\left(232 \pm 22 \times 10^{-5} \mathrm{~K}^{-1}\right)$. Importantly, this value substantially exceeds the thermal expansivity coefficient of the bulk buffer $\left(\alpha_{0}=26.9 \pm 1.3 \times 10^{-5} \mathrm{~K}^{-1}\right)$, clearly confirming that water organization changes with temperature more near the solute surface than in the bulk.

\section{DISCUSSION}

4.1. Comparison of the Canonical Bromobenzotriazole hCK $2 \alpha$ Complexes with Prior Structures. Benzotriazole and purine scaffolds are almost isostructural. Compared to the purines in ATP or GTP, ${ }^{67-69}$ the canonically bound benzotriazoles are located deeper in the pocket and further away from the hinge region (Figure $S 9 A B$ ). For benzotriazoles with bromo substituents in the 5 or 6 positions, the displacement avoids a steric conflict with the hinge (V116). Instead, one of the 5 or 6 halogen atoms adopts a position similar to that of the N6 atom of adenine. In the case of adenine, the exocyclic N6 amino group donates a hydrogen bond to the carbonyl oxygen atom of E114. For 5- or 6substituted bromobenzotriazoles the $\sigma$-hole of the bromine atom could mimic electron-accepting properties of the N6 amino group. However, in the canonical hCK $2 \alpha$ bromobenzotriazole complex structures, the distances between the backbone carbonyl oxygen atoms of E114 (and V116) from the hinge region of hCK $2 \alpha$ and the bromine atoms are longer than the $3.4 \AA$ sum of van der Waals radii of oxygen and bromine. $^{70}$ Therefore, their location in the crystal structure is not indicative of halogen bonding. Instead the triazole part of the ligands tends to occupy a position close to that of the ATP $\alpha$-phosphate oxygen atom and thus mimic its ionic interaction with the K68 at the bottom of the pocket.

4.2. "Noncanonical" Bromobenzotriazole hCK $2 \alpha$ Complexes vs Prior Structures. TBBt and $4,7-\mathrm{Br}_{2} \mathrm{Bt}$ are bound less deeply in the pocket of $\mathrm{hCK} 2 \alpha$ compared to the canonical pose because the ligand would otherwise clash with the pocket walls. As a result, at least the tetrabromobenzotriazole tends to overlap better with the inferred binding of the ATP purine (Figure S9CD). The ligand not only binds in a shallower manner but also comes closer to the hinge, at least in some of the binding poses. This opens up the possibility of halogen bonding with the main chain carbonyl oxygen atoms of the hinge region. In this respect, the noncanonical binding mode of the benzotriazoles is similar to the binding mode of tetrabromobenzotriazole analogues with extra steric bulk on the triazole side, which are also pushed closer to the hinge region. ${ }^{30}$ It is instructive to compare the binding modes of TBBt to human CK2 $\alpha$ with previously observed ones. All previous studies of TBBt complexes with maize CK2 $2 \alpha^{38}$ and human $\mathrm{CDK} 2^{39}$ and of a TBBt derivative with human CK2 $2 \alpha^{\prime 45}$ have reported a single ligand -binding pose. Interestingly, structural alignment shows that the alternative poses observed for TBBt in this work share the same space, with particularly good overlap of the halogen atom locations. The orientation of TBBt and its analogues in almost all complexes of CK2 with bisubstrate inhibitors ${ }^{26-29}$ is also consistent with the poses observed in our structure (Figure S10). The multiple TBBt poses observed by us and others suggest that the precise binding mode is not well-defined for this ligand. Thus, the thermodynamic contribution associated with the burial of its large hydrophobic surface in the nonpolar ATP-binding pocket of the kinase may predominate over specific interactions. This conclusion is in line with the review demonstrating that hydrophobic contacts determine the binding affinity (inhibitory activity) of halogenated benzotriazoles and benzimidazoles to protein kinases. ${ }^{41}$ Moreover, the "noncanonical" locations of TBBt display short contacts between bromine atoms and carbonyl oxygen atoms of E114 and V116 (Figures 1 and 2, poses close to the hinge). This is in line with our recent thermodynamic study of the four possible isomeric forms of dibromo-dichlorobenzotriazole, of which 5,6- $\mathrm{Br}_{2}-4,7$ $\mathrm{Cl}_{2} \mathrm{Bt}$ has the highest affinity to hCK $2 \alpha{ }^{37}$ This result suggests that, at least in solution, the binding of perhalogenated benzotriazoles might be accompanied by two halogen bonds involving substituents in positions 5 and 6 .

4.3. Hydrophobic Effect and the Decrease in the Isobaric Heat Capacity. The affinity of bromobenzotriazoles to $\mathrm{hCK} 2 \alpha$ increases with the number of bromine atoms. Halogen substitutions in the 5 and 6 positions have larger effects than those in the 4 and 7 positions. Thermodynamic 
data point to the hydrophobic effect as an important contributor to binding. The strong entropic component can be attributed to the release of highly ordered water molecules from the surfaces of the ligand and binding cavity. The most widely accepted signature of hydrophobically driven interaction is a decrease in the isobaric heat capacity $\left(\Delta C_{p, \text { bind }}<\right.$ $0) .{ }^{71}$ Such a decrease is indeed observed in our experiments. In macromolecular crystallography, it is generally believed that for a large macromolecular surface the $\Delta C_{p \text {,bind }}$ values are proportional to the solvent accessible surface area ( $\Delta \mathrm{ASA})$ that is buried in the binding event. We have tested several parametrizations that correlate the reduction of polar and nonpolar solvent accessible surfaces upon ligand binding ( $\triangle \mathrm{ASA})$ with the heat capacity change associated with this process, ${ }^{72-75}$ but none of them properly predicted experimental values (Table S3, Figure S11A-D). Instead, we see a more pronounced drop in the heat capacity for the more highly substituted and therefore larger bromobenzotriazoles. The $\Delta C_{p \text {,bind }}$ value increases more strongly with the number of bromo substituents than a surface (or volume) argument suggests (Figure 4A). In the case of the number of bromo substituents as the independent variable, the correlation can be approximated by a linear relationship with no significant offset
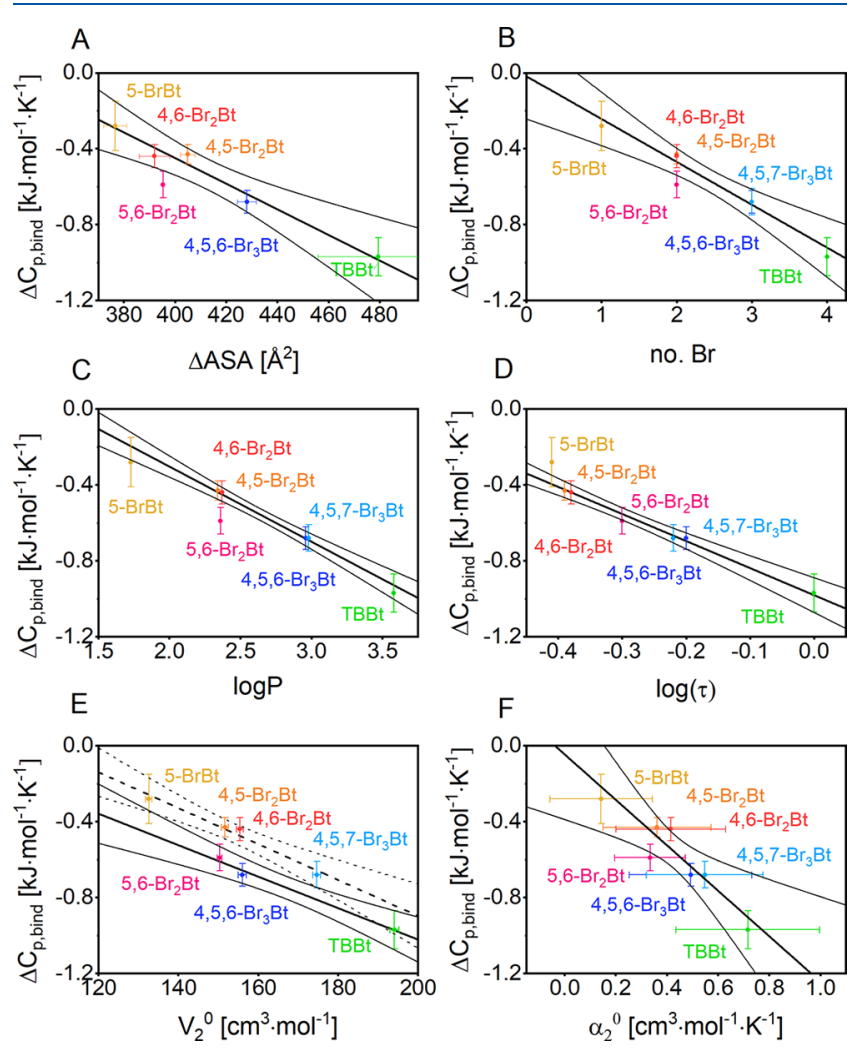

Figure 4. Heat capacity changes $\left(\Delta C_{p, \text { bind }}\right)$ associated with the hCK2 $\alpha$-bromobenzotriazole interaction. $\Delta C_{p, \text { bind }}$ values were correlated with $(\mathrm{A})$ the change in the solvent accessible surface of the ligand and the protein, (B) number of bromo substituents, (C) calculated water-octanol partition coefficient $\log (P),{ }^{36}$ (D) previously measured HPLC-derived hydrophobicity data, $\log (\tau),{ }^{37}$ and (E, F) $V_{0}^{2}$ and $\alpha$, respectively. In (C) and (E) $5,6-\mathrm{Br}_{2} \mathrm{Bt}$ was excluded from the regression analysis. Note that the scale on the abscissa does not start at 0 . None of the relationships is therefore a proportion, but the dependence of $\Delta C_{p, \text { bind }}$ on the number of bromo substituents comes close to such a relationship. Thin lines represent $95 \%$ confidence bands for the fitted line. from the origin (Figure 4B). There are several explanations of this effect that are not mutually exclusive.

First, the $\Delta C_{p \text {,bind }}$ correction may depend on the degree of hydrophobicity. This factor may be similar to other measures of hydrophobicity, such as the water-octanol partition coefficient $(\log P)^{36,37}$ or the partial molar volume, ${ }^{36}$ even though molecular explanations for the $\Delta C_{p, \text { bind }}$ effect $^{76,77}$ treat hydrophobicity as a qualitative rather than a quantitative property. Indeed, Spolar parametrization extended for bromine (3.47 $\mathrm{J} \cdot \mathrm{mol}^{-1} \cdot \mathrm{K}^{-1} \cdot \AA^{-2}$ ) reliably predicts all experimental $\Delta C_{p, \text { bind }}$ values (Figure $\mathrm{S} 11 \mathrm{E}$ ). This clearly indicates that hydrophobic contribution of $\mathrm{Br}$ is approximately 2.5 -fold larger than that estimated for hydrocarbons $\left(1.34 \mathrm{~J} \cdot \mathrm{mol}^{-1} \cdot \mathrm{K}^{-1}\right.$. $\left.\AA^{-2}\right){ }^{73}$ Second, electrostatic interactions with solvating water molecules decrease the heat capacity of the charged compounds. ${ }^{78}$ Upon binding events this will be reflected in heat capacity changes less negative than for the neutral counterparts. We have tested the dependence of $\Delta C_{p, \text { bind }}$ on the water octanol partition coefficient, $\log P$ (Figure $4 \mathrm{C})$, and a hydrophobicity measure based on HPLC retention times, $\log (\tau)$ (Figure 4D). Both dependencies can be described by linear regression. Two ligands $\left(5-\mathrm{BrBt}\right.$ and $\left.5,6-\mathrm{Br}_{2} \mathrm{Bt}\right)$ were not consistent with the regression line relating $\Delta C_{p, \text { bind }}$ values and the commonly used in silico derived hydrophobicity indicators $(\triangle \mathrm{ASA}, \log P)$. Since a relevant fraction of these two ligands is neutral at $\mathrm{pH} 8.0$ (0.26 and 0.08 , respectively $),{ }^{46}$ one may assume that the contribution of particular electrostatic interactions should be reflected in $\Delta C_{p \text {,bind }}$ values. Finally, the $\Delta C_{p, \text { bind }}$ change could also be due to the changes in protein conformation.

4.4. Entropic Balance and Conformational Change in the Protein upon Ligand Binding. Following the idea of Spolar and Record, ${ }^{79}$ the entropic change associated with ligand binding can be broken down into three main entropic components, the loss of rotational and translational degrees of freedom $\Delta S_{\mathrm{rt}}$ the hydrophobic effect $\Delta S_{\mathrm{HE}}$, and the reminder $\Delta S_{\text {other }}$. Due to the rigidity of the brominated benzotriazoles, $\Delta S_{\text {other }}$ is most likely attributable to changes in the protein conformation and order. The other two contributions to entropic change can be estimated with known formulas.

The entropy decrease resulting from the loss of rotational and translational degrees of freedom can be calculated based on the following equation. ${ }^{80}$ Please note that we have neglected a minute correction $\left(\sim 6 \mathrm{~J} \cdot \mathrm{mol}^{-1} \cdot \mathrm{K}^{-1}\right)$ that allows for the difference between the temperature $T$ of interest and the reference temperature $T_{\text {ref }}$ for which the formula was originally developed ( $m$ is the molecular mass of the ligand):

$$
\Delta S_{\mathrm{rt}}=-57 \mathrm{~J} \cdot \mathrm{mol}^{-1} \cdot \mathrm{K}^{-1}-5 \cdot R \cdot \ln \left(m \mathrm{Da}^{-1}\right)
$$

The change in heat capacity $\Delta C_{p, \text { bind }}$ predicts a proportional entropy change that depends on the logarithm of temperature.

$$
\Delta S_{\mathrm{HE}}=-1.35 \cdot \Delta C_{p, \text { bind }} \cdot \ln \left(T / 386 \mathrm{~K}^{-1}\right)
$$

From the experimental dependence of the total entropy change on temperature, we can extrapolate the temperature $T_{\mathrm{s}}$ where the total entropy change is 0 (Figure S6DF and Table S4). At this temperature

$$
0=\Delta S_{\text {bind }}\left(T_{\mathrm{s}}\right)=\Delta S_{\mathrm{rt}}+\Delta S_{\mathrm{HE}}\left(T_{\mathrm{s}}\right)+\Delta S_{\text {other }}
$$

The $\Delta S_{\text {other }}$ contribution can be directly calculated using this expression (Table S4). Our data suggest that the $\Delta S_{\text {other }}$ contribution is relatively minor for $\mathrm{TBBt}, 4,5,6-\mathrm{Br}_{3} \mathrm{Bt}$, and 
A

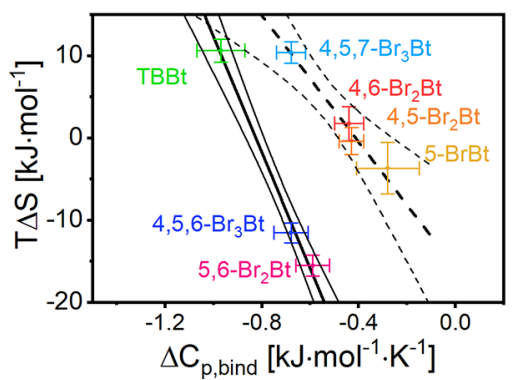

B

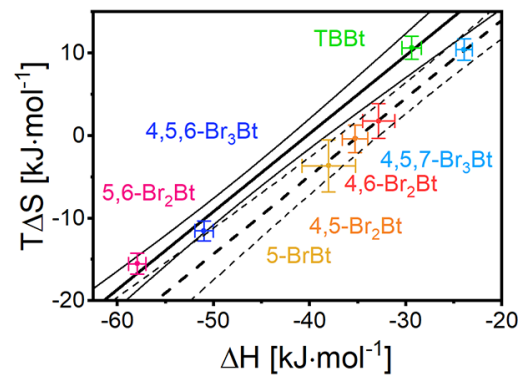

Figure 5. Correlation between principal thermodynamic parameters associated with ligand binding. (A) Two commonly accepted descriptors of the hydrophobic contribution to the free energy of ligand-binding cluster benzotriazoles into two groups. (B) The same groups are identifiable in entropy-enthalpy compensation observed at $25{ }^{\circ} \mathrm{C}$. The two parallel lines are separated by $\sim 4.9 \mathrm{~kJ} \cdot \mathrm{mol}^{-1}$, which strictly corresponds to the free energy difference between strongly and weakly binding bromobenzotriazoles.

$5,6-\mathrm{Br}_{2} \mathrm{Bt}$ but equals $100-200 \mathrm{~J} \cdot \mathrm{mol}^{-1} \cdot \mathrm{K}^{-1}$ for the other bromobenzotriazoles. According to Spolar and Record, the $\Delta S_{\text {other }}$ entropy change of $\sim 100 \mathrm{~J} \cdot \mathrm{mol}^{-1} \cdot \mathrm{K}^{-1}$ is indicative for partial unfolding of 5-6 residues. ${ }^{79}$ Residues ${ }^{30}$ VVEWGNQD ${ }^{37}$ of hCK $2 \alpha$ are disordered in the complexes with large $\Delta S_{\text {other, }}$ but not in those with $\Delta S_{\text {other }}$ close to zero (Figure S12). This suggests that this region may be important for the protein contribution to entropic change, but since the structures include an almost 60 amino acid long disordered region at the $\mathrm{C}$-terminus of the kinase (not visible in the crystal structures), this assignment remains speculative.

4.5. Grouping Brominated Benzotriazoles Based on Thermodynamic Data. According to the heat capacity upon ligand binding $\left(\Delta C_{p, \text { bind }}\right)$ and partial molar volume $\left(V_{2}^{0}\right)$, the bromobenzotriazoles cluster into groups that differ in the substitution pattern (Figure 4E, according to the F-test, the alternative model with no grouping must be rejected at $p \sim$ $\left.10^{-4} ; F(1,5)=57\right)$. Such a tendency may be discerned also for solute thermal expansivity (Figure 4F, according to the F-test, the alternative model with no grouping must be rejected at $p=$ 0.023; $F(1,4)=12.6)$. Taken together, the thermodynamic data clearly show interplay between the direct hydrophobic effect, roughly represented by the number of bromine atoms in the molecule, and the halogen-induced changes of the ligand electronic properties related to the apparent polarity of the compound.

$T \Delta S$ and $\Delta C_{p, \text { bind }}$ are commonly used thermodynamic descriptors of the hydrophobic contribution to ligand binding. They cluster bromobenzotriazoles in the same groups (Figure $5 \mathrm{~A}$, according to the F-test, the alternative model with no grouping must be rejected at $\left.p \sim 10^{-4} ; F(2,3)=600\right)$. Similar trends have been reported for the $\mathrm{IC}_{50}$ values (Table 2). ${ }^{32}$ Moreover, the same regularity is observed for entropyenthalpy compensation (Figure 5B, the alternative model assuming one group of ligands must be rejected at $p=0.003$; $F(1,4)=43.7)$, for which two parallel lines of the $0.965 \pm$ 0.026 slope indicate an almost perfect compensation among the grouped ligands. Such compensation is commonly observed for protein-ligand ${ }^{81}$ and protein-protein ${ }^{82}$ systems. The distance between the lines (estimated to be $4.9 \mathrm{~kJ} \cdot \mathrm{mol}^{-1}$ from the intercept values) reflects the difference in the free energy of protein-ligand interaction observed for strongly (5,6- $\mathrm{Br}_{2} \mathrm{Bt}, 4,5,6-\mathrm{Br}_{3} \mathrm{Br}$, TBBt) and weakly $\left(5-\mathrm{BrBt}, 4,5-\mathrm{Br}_{2} \mathrm{Bt}\right.$, 4,6- $-\mathrm{Br}_{2} \mathrm{Bt}, 4,5,7-\mathrm{Br}_{3} \mathrm{Br}$ ) binding ligands (Table 3). The systematic discrepancies strongly support the presence of two competing mechanisms of bromobenzotriazole hCK2 $\alpha$ bind- ing-one for high-affinity ligands, in which both 5 and 6 positions are brominated, and the other one for ligands in which one of the two positions remains unsubstituted.

\section{CONCLUSIONS}

Ligand-binding poses of brominated benzotriazoles in the CK2 active site are dictated by three competing drivers. These are salt bridge or hydrogen bond formation with K68, halogen bond formation with the linker region, and the hydrophobic effect. Salt bridge or hydrogen bond formation on the one hand and halogen bonding on the other hand are largely mutually exclusive because the hCK $2 \alpha$ linker region and K68 are too far apart for both interactions to occur simultaneously. Salt bridge formation typically wins over halogen bonding unless the former is sterically disfavored (as in 4,7-substituted benzotriazoles). The hydrophobic effect plays a dominant role in bromobenzotriazole $\mathrm{hCK} 2 \alpha$ binding. Its contribution is evidenced by the strong entropic drive (caused by the release of water molecules from the ligand surface into the bulk solvent) and by the negative $\Delta C_{p, \text { bind }}$. For the most highly brominated ligand (TBBt), the hydrophobic effect is so dominant that the ligand explores almost the entire cavity, thus forgoing in some poses the favorable interaction with K68.

\section{ASSOCIATED CONTENT}

\section{SI Supporting Information}

The Supporting Information is available free of charge at https://pubs.acs.org/doi/10.1021/acs.jpcb.0c10264.

Supplementary figures and tables providing more detailed depiction of the presented data (PDF)

\section{Accession Codes}

Protein Data Bank (PDB) accession numbers: hCK2 $\alpha-4-\mathrm{BrBt}$ 6TLW, hCK $2 \alpha-5-\mathrm{BrBt} 6 \mathrm{TLV}, \mathrm{hCK} 2 \alpha-4,5-\mathrm{Br}_{2} \mathrm{Bt} 6 \mathrm{TLU}$, hCK $2 \alpha-4,6-\mathrm{Br}_{2} \mathrm{Bt}$ 6TLS, hCK $2 \alpha-4,7-\mathrm{Br}_{2} \mathrm{Bt}$ 6TLR, hCK2 $\alpha$ 5,6-Br $\mathrm{B}_{2} \mathrm{Bt}$ 6TLP, hCK $2 \alpha-4,5,6-\mathrm{Br}_{3} \mathrm{Bt}$ 6TLO, hCK $2 \alpha-\mathrm{TBBt}$ 6TLL.

\section{AUTHOR INFORMATION}

\section{Corresponding Authors}

Matthias Bochtler - Institute of Biochemistry and Biophysics PAS, 02-106 Warsaw, Poland; International Institute of Molecular and Cell Biology, 02-109 Warsaw, Poland;

Phone: +48 22 5970732; Email: mbochtler@iimcb.gov.pl; Fax: +48 225970715 
Jarosław Poznański - Institute of Biochemistry and Biophysics PAS, 02-106 Warsaw, Poland; (1) orcid.org/0000-00032684-1775; Phone: +48 22 5925783; Email: jarek@ ibb.waw.pl; Fax: +48 225922190

\section{Authors}

Honorata Czapinska - Institute of Biochemistry and Biophysics PAS, 02-106 Warsaw, Poland; International Institute of Molecular and Cell Biology, 02-109 Warsaw, Poland

Maria Winiewska-Szajewska - Institute of Biochemistry and Biophysics PAS, 02-106 Warsaw, Poland; Department of Biophysics, Institute of Experimental Physics, University of Warsaw, 02-089 Warsaw, Poland

Anna Szymaniec-Rutkowska - Institute of Biochemistry and Biophysics PAS, 02-106 Warsaw, Poland

Anna Piasecka - Institute of Biochemistry and Biophysics PAS, 02-106 Warsaw, Poland; International Institute of Molecular and Cell Biology, 02-109 Warsaw, Poland

Complete contact information is available at:

https://pubs.acs.org/10.1021/acs.jpcb.0c10264

\section{Author Contributions}

${ }^{\perp}$ These authors contributed equally.

\section{Notes}

The authors declare no competing financial interest.

\section{ACKNOWLEDGMENTS}

This work was supported by Polish National Science Center grants 2012/07/B/ST4/01334 2015/19/B/ST4/02156 and 2017/25/B/ST4/01613. Synchrotron data collections were partly funded by the Seventh Framework Program of the European Community (FP7/2007-2013) under the BioStruct$\mathrm{X}$ grant agreement (No. 283570). Data for this project were collected at the MX1 and MX2 beamlines of the DESY PETRA storage ring (Hamburg, Germany), the 14.1 beamline of the BESSY synchrotron (Berlin, Germany), and the XRD1 beamline of ELETTRA (Trieste, Italy). We are grateful for beamline access and assistance during data collection.

\section{REFERENCES}

(1) Meggio, F.; Pinna, L. A. One-thousand-and-one substrates of protein kinase CK2? FASEB J. 2003, 17, 349-368.

(2) Gietz, R. D.; Graham, K. C.; Litchfield, D. W. Interactions between the subunits of casein kinase II. J. Biol. Chem. 1995, 270, 13017-13021.

(3) Manning, G.; Whyte, D. B.; Martinez, R.; Hunter, T.; Sudarsanam, S. The protein kinase complement of the human genome. Science 2002, 298, 1912-1934.

(4) Lou, D. Y.; Dominguez, I.; Toselli, P.; Landesman-Bollag, E.; O'Brien, C.; Seldin, D. C. The alpha catalytic subunit of protein kinase CK2 is required for mouse embryonic development. Mol. Cell. Biol. 2008, 28, 131-139.

(5) Xu, X.; Toselli, P. A.; Russell, L. D.; Seldin, D. C. Globozoospermia in mice lacking the casein kinase II alpha' catalytic subunit. Nat. Genet. 1999, 23, 118-121.

(6) Ahmed, K.; Gerber, D. A.; Cochet, C. Joining the cell survival squad: an emerging role for protein kinase CK2. Trends Cell Biol. 2002, 12, 226-230.

(7) Ruzzene, M.; Pinna, L. A. Addiction to protein kinase CK2: a common denominator of diverse cancer cells? Biochim. Biophys. Acta, Proteins Proteomics 2010, 1804, 499-504.

(8) Ferguson, A. D.; Sheth, P. R.; Basso, A. D.; Paliwal, S.; Gray, K.; Fischmann, T. O.; Le, H. V. Structural basis of CX-4945 binding to human protein kinase CK2. FEBS Lett. 2011, 585, 104-110.
(9) Siddiqui-Jain, A.; Drygin, D.; Streiner, N.; Chua, P.; Pierre, F.; O'Brien, S. E.; Bliesath, J.; Omori, M.; Huser, N.; Ho, C.; et al. CX4945 , an orally bioavailable selective inhibitor of protein kinase CK2, inhibits prosurvival and angiogenic signaling and exhibits antitumor efficacy. Cancer Res. 2010, 70, 10288-10298.

(10) Pierre, F.; Chua, P. C.; O’Brien, S. E.; Siddiqui-Jain, A.; Bourbon, P.; Haddach, M.; Michaux, J.; Nagasawa, J.; Schwaebe, M. K.; Stefan, E.; et al. Discovery and SAR of 5-(3-chlorophenylamino)benzo[c][2,6]naphthyridine-8-carboxylic acid (CX-4945), the first clinical stage inhibitor of protein kinase CK2 for the treatment of cancer. J. Med. Chem. 2011, 54, 635-654.

(11) Kim, H. M.; Jeong, I.; Kim, H. J.; Kang, S. K.; Kwon, W. S.; Kim, T. S.; Park, K. H.; Jung, M.; Soong, J.; Lin, S. C.; et al. Casein kinase 2 inhibitor, CX-4945, as a potential targeted anticancer agent in gastric cancer. Anticancer Res. 2018, 38, 6171-6180.

(12) Gowda, C.; Sachdev, M.; Muthusami, S.; Kapadia, M.; PetrovicDovat, L.; Hartman, M.; Ding, Y.; Song, C.; Payne, J. L.; Tan, B. H.; et al. Casein kinase II (CK2) as a therapeutic target for hematological malignancies. Curr. Pharm. Des. 2017, 23, 95-107.

(13) Chon, H. J.; Bae, K. J.; Lee, Y.; Kim, J. The casein kinase 2 inhibitor, CX-4945, as an anti-cancer drug in treatment of human hematological malignancies. Front. Pharmacol. 2015, 6, 70.

(14) Zakharia, K.; Miyabe, K.; Wang, Y.; Wu, D. H.; Moser, C. D.; Borad, M. J.; Roberts, L. R. Preclinical in vitro and In vivo evidence of an antitumor effect of CX-4945, a casein kinase II Inhibitor, in Cholangiocarcinom. Transl. Oncol. 2019, 12, 143-153.

(15) Niefind, K.; Guerra, B.; Pinna, L. A.; Issinger, O. G.; Schomburg, D. Crystal structure of the catalytic subunit of protein kinase CK2 from Zea mays at 2.1 A resolution. EMBO J. 1998, 17, 2451-2462.

(16) Niefind, K.; Guerra, B.; Ermakowa, I.; Issinger, O. G. Crystal structure of human protein kinase CK2: insights into basic properties of the CK2 holoenzyme. EMBO J. 2001, 20, 5320-5331.

(17) Taylor, S. S.; Kornev, A. P. Protein kinases: evolution of dynamic regulatory proteins. Trends Biochem. Sci. 2011, 36, 65-77.

(18) Fabbro, D.; Cowan-Jacob, S. W.; Moebitz, H. Ten things you should know about protein kinases: IUPHAR Review 14. Br. J. Pharmacol. 2015, 172, 2675-2700.

(19) Adams, J. A. Kinetic and catalytic mechanisms of protein kinases. Chem. Rev. 2001, 101, 2271-2290.

(20) Niefind, K.; Issinger, O. G. Conformational plasticity of the catalytic subunit of protein kinase CK2 and its consequences for regulation and drug design. Biochim. Biophys. Acta, Proteins Proteomics 2010, 1804, 484-492.

(21) Raaf, J.; Issinger, O. G.; Niefind, K. First inactive conformation of CK2 alpha, the catalytic subunit of protein kinase CK2. J. Mol. Biol. 2009, 386, 1212-1221.

(22) Olsen, B. B.; Guerra, B.; Niefind, K.; Issinger, O. G. Structural basis of the constitutive activity of protein kinase CK2. Methods Enzymol. 2010, 484, 515-529.

(23) Roskoski, R., Jr. Classification of small molecule protein kinase inhibitors based upon the structures of their drug-enzyme complexes. Pharmacol. Res. 2016, 103, 26-48.

(24) Szyszka, R.; Grankowski, N.; Felczak, K.; Shugar, D. Halogenated benzimidazoles and benzotriazoles as selective inhibitors of protein kinases CK I and CK II from Saccharomyces cerevisiae and other sources. Biochem. Biophys. Res. Commun. 1995, 208, 418-424.

(25) Sarno, S.; Reddy, H.; Meggio, F.; Ruzzene, M.; Davies, S. P.; Donella-Deana, A.; Shugar, D.; Pinna, L. A. Selectivity of 4,5,6,7tetrabromobenzotriazole, an ATP site-directed inhibitor of protein kinase CK2 ('casein kinase-2'). FEBS Lett. 2001, 496, 44-48.

(26) Pietsch, M.; Viht, K.; Schnitzler, A.; Ekambaram, R.; Steinkruger, M.; Enkvist, E.; Nienberg, C.; Nickelsen, A.; Lauwers, M.; Jose, J.; et al. Unexpected CK2beta-antagonistic functionality of bisubstrate inhibitors targeting protein kinase CK2. Bioorg. Chem. 2020, 96, 103608.

(27) Chojnacki, K.; Winska, P.; Wielechowska, M.; LukowskaChojnacka, E.; Tolzer, C.; Niefind, K.; Bretner, M. Biological properties and structural study of new aminoalkyl derivatives of 
benzimidazole and benzotriazole, dual inhibitors of CK2 and PIM1 kinases. Bioorg. Chem. 2018, 80, 266-275.

(28) Cozza, G.; Girardi, C.; Ranchio, A.; Lolli, G.; Sarno, S.; Orzeszko, A.; Kazimierczuk, Z.; Battistutta, R.; Ruzzene, M.; Pinna, L. A. Cell-permeable dual inhibitors of protein kinases CK2 and PIM-1: structural features and pharmacological potential. Cell. Mol. Life Sci. 2014, 71, 3173-3185.

(29) Enkvist, E.; Viht, K.; Bischoff, N.; Vahter, J.; Saaver, S.; Raidaru, G.; Issinger, O. G.; Niefind, K.; Uri, A. A subnanomolar fluorescent probe for protein kinase CK2 interaction studies. Org. Biomol. Chem. 2012, 10, 8645-8653.

(30) Battistutta, R.; Mazzorana, M.; Sarno, S.; Kazimierczuk, Z.; Zanotti, G.; Pinna, L. A. Inspecting the structure-activity relationship of protein kinase CK2 inhibitors derived from tetrabromobenzimidazole. Chem. Biol. 2005, 12, 1211-1219.

(31) Brzozka, K.; Czardybon, W.; Golas, A.; Windak, R.; Galezowski, M.; Gabor-Worwa, E.; Winnik, B.; Przybylowicz, A.; Szydlowski, M.; Bialopiotrowicz, E.; et al. First-in-class dual PIM/FLT3 kinase inhibitor SEL24-B489 for the treatment of hematological malignancies. Cancer Res. 2015, 75.

(32) Wasik, R.; Wińska, P.; Poznański, J.; Shugar, D. Isomeric mono-, di-, and tri-bromobenzo- $1 \mathrm{H}$-triazoles as inhibitors of human protein kinase CK2 $\alpha$. PLoS One 2012, 7, e48898.

(33) Winiewska, M.; Kucinska, K.; Makowska, M.; Poznanski, J.; Shugar, D. Thermodynamics parameters for binding of halogenated benzotriazole inhibitors of human protein kinase CK2 alpha. Biochim. Biophys. Acta, Proteins Proteomics 2015, 1854, 1708-1717.

(34) Winiewska, M.; Makowska, M.; Maj, P.; Wielechowska, M.; Bretner, M.; Poznanski, J.; Shugar, D. Thermodynamic parameters for binding of some halogenated inhibitors of human protein kinase CK2. Biochem. Biophys. Res. Commun. 2015, 456, 282-287.

(35) Winiewska, M.; Bugajska, E.; Poznanski, J. ITC-derived binding affinity may be biased due to titrant (nano)-aggregation. Binding of halogenated benzotriazoles to the catalytic domain of human protein kinase CK2. PLoS One 2017, 12, e173260.

(36) Szymaniec-Rutkowska, A.; Bugajska, E.; Kasperowicz, S.; Mieczkowska, K.; Maciejewska, A. M.; Poznanski, J. Does the partial molar volume of a solute reflect the free energy of hydrophobic solvation? J. Mol. Liq. 2019, 293, 111527.

(37) Kasperowicz, S.; Marzec, E.; Maciejewska, A. M.; Trzybinski, D.; Bretner, M.; Wozniak, K.; Poznanski, J.; Mieczkowska, K. A competition between hydrophobic and electrostatic interactions in protein-ligand systems. Binding of heterogeneously halogenated benzotriazoles by the catalytic subunit of human protein kinase CK2. IUBMB Life 2020, 72, 1211-1219.

(38) Battistutta, R.; De Moliner, E.; Sarno, S.; Zanotti, G.; Pinna, L. A. Structural features underlying selective inhibition of protein kinase CK2 by ATP site-directed tetrabromo-2-benzotriazole. Protein Sci. 2001, 10, 2200-2206.

(39) De Moliner, E.; Brown, N. R.; Johnson, L. N. Alternative binding modes of an inhibitor to two different kinases. Eur. J. Biochem. 2003, 270, 3174-3181.

(40) Bischoff, N.; Raaf, J.; Olsen, B.; Bretner, M.; Issinger, O. G.; Niefind, K. Enzymatic activity with an incomplete catalytic spine: insights from a comparative structural analysis of human CK2alpha and its paralogous isoform CK2alpha'. Mol. Cell. Biochem. 2011, 356, $57-65$.

(41) Battistutta, R.; Mazzorana, M.; Cendron, L.; Bortolato, A.; Sarno, S.; Kazimierczuk, Z.; Zanotti, G.; Moro, S.; Pinna, L. A. The ATP-binding site of protein kinase CK2 holds a positive electrostatic area and conserved water molecules. ChemBioChem 2007, 8, 18041809.

(42) Sarno, S.; Papinutto, E.; Franchin, C.; Bain, J.; Elliott, M.; Meggio, F.; Kazimierczuk, Z.; Orzeszko, A.; Zanotti, G.; Battistutta, R; et al. ATP site-directed inhibitors of protein kinase CK2: an update. Curr. Top. Med. Chem. 2011, 11, 1340-1351.

(43) Raaf, J.; Brunstein, E.; Issinger, O. G.; Niefind, K. The CK2 alpha/CK2 beta interface of human protein kinase CK2 harbors a binding pocket for small molecules. Chem. Biol. 2008, 15, 111-117.
(44) Poznanski, J.; Winiewska, M.; Czapinska, H.; Poznanska, A.; Shugar, D. Halogen bonds involved in binding of halogenated ligands by protein kinases. Acta Biochim. Polym. 2016, 63, 203-214.

(45) Bischoff, N.; Olsen, B.; Raaf, J.; Bretner, M.; Issinger, O. G.; Niefind, K. Structure of the human protein kinase CK2 catalytic subunit CK2alpha' and interaction thermodynamics with the regulatory subunit CK2beta. J. Mol. Biol. 2011, 407, 1-12.

(46) Wasik, R.; Winska, P.; Poznanski, J.; Shugar, D. Synthesis and physico-chemical properties in aqueous medium of all possible isomeric bromo analogues of benzo- $1 \mathrm{H}$-triazole, potential inhibitors of protein kinases. J. Phys. Chem. B 2012, 116, 7259-7268.

(47) Vagin, A.; Teplyakov, A. MOLREP: an automated program for molecular replacement. J. Appl. Crystallogr. 1997, 30, 1022-1025.

(48) Kinoshita, T.; Nakaniwa, T.; Sekiguchi, Y.; Sogabe, Y.; Sakurai, A.; Nakamura, S.; Nakanishi, I. Crystal structure of human CK2alpha at 1.06 A resolution. J. Synchrotron Radiat. 2013, 20, 974-979.

(49) Langer, G.; Cohen, S. X.; Lamzin, V. S.; Perrakis, A. Automated macromolecular model building for X-ray crystallography using ARP/ wARP version 7. Nat. Protoc. 2008, 3, 1171-1179.

(50) Murshudov, G. N.; Skubak, P.; Lebedev, A. A.; Pannu, N. S.; Steiner, R. A.; Nicholls, R. A.; Winn, M. D.; Long, F.; Vagin, A. A. REFMAC5 for the refinement of macromolecular crystal structures. Acta Crystallogr., Sect. D: Biol. Crystallogr. 2011, 67, 355-367.

(51) Schuttelkopf, A. W.; van Aalten, D. M. PRODRG: a tool for high-throughput crystallography of protein-ligand complexes. Acta Crystallogr., Sect. D: Biol. Crystallogr. 2004, 60, 1355-1363.

(52) Marquardt, D. W. An algorithm for least-squares estimation of nonlinear parameters. J. Soc. Ind. Appl. Math. 1963, 11, 431-441.

(53) Eftink, M. R. The use of fluorescence methods to monitor unfolding transitions in proteins. Biophys. J. 1994, 66, 482-501.

(54) Poznanski, J.; Wszelaka-Rylik, M.; Zielenkiewicz, W. Concentration dependencies of $\mathrm{NaCl}$ salting of lysozyme by calorimetric methods. Thermochim. Acta 2004, 409, 25-32.

(55) Poznanski, J.; Wszelaka-Rylik, M.; Zielenkiewicz, W. HEW lysozyme salting by high-concentration $\mathrm{NaCl}$ solutions followed by titration calorimetry. Biophys. Chem. 2005, 113, 137-144.

(56) Baranauskiene, L.; Petrikaite, V.; Matuliene, J.; Matulis, D. Titration calorimetry standards and the precision of isothermal titration calorimetry data. Int. J. Mol. Sci. 2009, 10, 2752-2762.

(57) Zielenkiewicz, W.; Poznanski, J. Partial molar volumes of hydrophobic compounds - Insight into the solvation shell? Part I. J. Solution Chem. 1998, 27, 245-254.

(58) Zielenkiewicz, W.; Poznanski, J.; Zielenkiewicz, A. Partial molar volumes of alkylated uracils - Insight into the solvation shell? Part II. J. Solution Chem. 1998, 27, 543-551.

(59) Frank, H. S.; Evans, M. W. Free volume and entropy in condensed systems 0.3. Entropy in binary liquid mixtures - partial molal entropy in dilute solutions - structure and thermodynamics in aqueous electrolytes. J. Chem. Phys. 1945, 13, 507-532.

(60) Kauzmann, W. Some factors in the interpretation of protein denaturation. Adv. Protein Chem. 1959, 14, 1-63.

(61) Lum, K.; Chandler, D.; Weeks, J. D. Hydrophobicity at small and large length scales. J. Phys. Chem. B 1999, 103, 4570-4577.

(62) Zielenkiewicz, W.; Poznanski, J. Partial molar volumes-insights into molecular structure. J. Mol. Liq. 1999, 81, 37-45.

(63) Poznanski, J. Partial molar volume as an important thermodynamic parameter. Application for uracil methyl derivatives. J. Mol. Liq. 2005, 121, 15-20.

(64) Kell, G. S. Density, thermal expansivity, and compressibility of liquid water from 0 degrees to 150 degrees - correlations and tables for atmospheric-pressure and saturation reviewed and expressed on 1968 temperature scale. J. Chem. Eng. Data 1975, 20, 97-105.

(65) Cooper, A. Heat capacity effects in protein folding and ligand binding: a re-evaluation of the role of water in biomolecular thermodynamics. Biophys. Chem. 2005, 115, 89-97.

(66) Cooper, A. Microcalorimetry of heat capacity and volumetric changes in biomolecular interactions-the link to solvation? J. Therm. Anal. Calorim. 2011, 104, 69-73. 
(67) Yde, C. W.; Ermakova, I.; Issinger, O. G.; Niefind, K. Inclining the purine base binding plane in protein kinase CK2 by exchanging the flanking side-chains generates a preference for ATP as a cosubstrate. J. Mol. Biol. 2005, 347, 399-414.

(68) Niefind, K.; Putter, M.; Guerra, B.; Issinger, O. G.; Schomburg, D. CTP plus water mimic ATP in the active site of protein kinase CK2. Nat. Struct. Biol. 1999, 6, 1100-1103.

(69) Kinoshita, T.; Sekiguchi, Y.; Fukada, H.; Nakaniwa, T.; Tada, T.; Nakamura, S.; Kitaura, K.; Ohno, H.; Suzuki, Y.; Hirasawa, A.; et al. A detailed thermodynamic profile of cyclopentyl and isopropyl derivatives binding to CK2 kinase. Mol. Cell. Biochem. 2011, 356, 97105.

(70) Bondi, A. Van der Waals volumes + radii. J. Phys. Chem. 1964, $68,441-451$.

(71) Spolar, R. S.; Ha, J. H.; Record, M. T., Jr. Hydrophobic effect in protein folding and other noncovalent processes involving proteins. Proc. Natl. Acad. Sci. U. S. A. 1989, 86, 8382-8385.

(72) Murphy, K. P.; Freire, E. Thermodynamics of Structural Stability and Cooperative Folding Behavior in Proteins. Adv. Protein Chem. 1992, 43, 313-361.

(73) Spolar, R. S.; Livingstone, J. R.; Record, M. T. Use of liquidhydrocarbon and amide transfer data to estimate contributions to thermodynamic functions of protein folding from the removal of nonpolar and polar surface from water. Biochemistry 1992, 31, 39473955.

(74) Myers, J. K.; Pace, C. N.; Scholtz, J. M. Denaturant m-values and heat-capacity changes - relation to changes in accessible surfaceareas of protein unfolding. Protein Sci. 1995, 4, 2138-2148.

(75) Makhatadze, G. I.; Privalov, P. L. Energetics of protein structure. Adv. Protein Chem. 1995, 47, 307-425.

(76) Galamba, N. Water's structure around hydrophobic solutes and the iceberg model. J. Phys. Chem. B 2013, 117, 2153-2159.

(77) Grdadolnik, J.; Merzel, F.; Avbelj, F. Origin of hydrophobicity and enhanced water hydrogen bond strength near purely hydrophobic solutes. Proc. Natl. Acad. Sci. U. S. A. 2017, 114, 322-327.

(78) Sturtevant, J. M. Heat-capacity and entropy changes in processes involving proteins. Proc. Natl. Acad. Sci. U. S. A. 1977, 74, 2236-2240.

(79) Spolar, R. S.; Record, M. T. Coupling of local folding to sitespecific binding of proteins to DNA. Science 1994, 263, 777-784.

(80) Murray, C. W.; Verdonk, M. L. The consequences of translational and rotational entropy lost by small molecules on binding to proteins. J. Comput.-Aided Mol. Des. 2002, 16, 741-753.

(81) Olsson, T. S. G.; Ladbury, J. E.; Pitt, W. R.; Williams, M. A. Extent of enthalpy-entropy compensation in protein-ligand interactions. Protein Sci. 2011, 20, 1607-1618.

(82) Olsson, T. S. G.; Williams, M. A.; Pitt, W. R.; Ladbury, J. E. The thermodynamics of protein-ligand interaction and solvation: insights for ligand design. J. Mol. Biol. 2008, 384, 1002-1017. 